OPEN ACCESS

Edited by:

Jue Wang,

The University of Texas Health Science Center at Tyler, United States

Reviewed by: Vincenzo Tufarelli, Università degli Studi di Bari, Italy Kyung-Woo Lee, Konkuk University, South Korea

${ }^{*}$ Correspondence: Yuming Guo

guoyum@cau.edu.cn

Specialty section

This article was submitted to Lipid and Fatty Acid Research, a section of the journal

Frontiers in Physiology

Received: 10 August 2018 Accepted: 03 October 2018 Published: 24 October 2018

Citation:

Lv Z, Xing K, Li G, Liu D and Guo Y (2018) Dietary Genistein Alleviates Lipid Metabolism Disorder and Inflammatory Response in Laying Hens With Fatty Liver Syndrome.

Front. Physiol. 9:1493 doi: 10.3389/fphys.2018.01493

\section{Dietary Genistein Alleviates Lipid Metabolism Disorder and Inflammatory Response in Laying Hens With Fatty Liver Syndrome}

\section{Zengpeng Lv, Kun Xing, Guang Li, Dan Liu and Yuming Guo* \\ State Key Laboratory of Animal Nutrition, College of Animal Science and Technology, China Agricultural University, Beijing, China}

This study investigated the molecular mechanism underlying the effect of dietary genistein (GEN) on fatty liver syndrome (FLS) in laying hens. Hens in the control group (CG) were fed a high-energy and low-choline (HELC) diet to establish the FLS model. The livers of the FLS hens were friable and swollen from hemorrhage. Hepatic steatosis and inflammatory cell infiltration were present around the liver blood vessels. Hens in the low-genistein (LGE) and high-genistein (he) groups were fed GEN at 40 and $400 \mathrm{mg} / \mathrm{kg}$ doses, respectively, as supplements to the HELC diet. GEN at $40 \mathrm{mg} / \mathrm{kg}$ significantly increased gonadotropin-releasing hormone $(\mathrm{GnRH}) \mathrm{mRNA}$ expression in the hypothalamus, the serum estrogen (E2) level, and the laying rate, whereas $400 \mathrm{mg} / \mathrm{kg}$ of GEN decreased $\mathrm{GnRH}$ expression and the laying rate without significantly affecting E2, suggesting that high-dose GEN adversely affected the reproductive performance. Either high- or low-dose GEN treatment could alleviate metabolic disorders and inflammatory responses in FLS hens. GEN significantly decreased the serum ALT, creatinine, triglyceride (TG), total cholesterol (TC), and free fatty acid (FFA) levels. Accordingly, the TG and long-chain fatty acid (LCFA) levels, including long-chain saturated fatty acids (LSFAs) and monounsaturated fatty acids (MUFAs), and the n-6:n-3 polyunsaturated fatty acid (PUFA) ratio in the liver were reduced after the GEN treatments, whereas the levels of C22:0, n-3 family fatty acids, C20:3n6, and C20:4n6 were increased. These results indicated that dietary GEN downregulated the expression of genes related to fatty acid synthesis [sterol regulatory element-binding protein 1 (SREBP1c), liver $X$ receptor alpha $(L X R \alpha)$, fatty acid synthase (FAS), and acetyl coenzyme $A$ synthetase (ACC)] and the fatty acid transporter (FAT). Furthermore, GEN treatments upregulated the transcription of genes related to fatty acid $\beta$-oxidation [peroxisome proliferator-activated receptor (PPAR) $\alpha$, PPAR $\delta$, ACOT8, ACAD8, and ACADs] in the liver and reduced PPAR $\gamma$ and AFABP expression in abdominal fat. Dietary GEN alleviated inflammatory cell infiltration in the livers of FLS hens and downregulated TNF- $\alpha$, IL-6, and IL-1 $\beta$ expression. Moreover, GEN treatment increased SOD activity 
and decreased malondialdehyde activity in the liver. In conclusion, GEN supplementation in the feed inhibited fatty acid synthesis and enhanced $\beta$-oxidation in the liver through the PPAR-ACAD/ACOT and PPAR-LXR $\alpha-S R E B P 1 C-A C C / F A S / F A T$ pathways. Dietary GEN alleviated metabolic disorder and inflammation in the FLS hens by improving the antioxidant capacity and fatty acid profile.

Keywords: genistein, hens, fatty liver, fatty acids, inflammation

\section{INTRODUCTION}

Fatty liver syndrome is one of the most common metabolic diseases in laying hens, especially during the late laying period. The FLS can significantly decrease egg production and induce sudden death, resulting in major economic losses for the poultry industry. Marked fatty degeneration and fat deposition occur in the parenchymal cells of the fatty liver (Giulio et al., 2003). The widely accepted "two-hit" theory indicates that disordered fatty acid metabolism is a common element of the FLS (Erickson, 2009). Thus, we speculated that high amounts of FFAs in the livers of hens during the late egg-laying period could destroy the structure of biofilms through free radicals. Excessive saturated fatty acids (SFAs) have been reported to not only have direct toxic effects on hepatocytes but to also indirectly cause cell damage (Kohjima et al., 2005). Furthermore, increased plasma FFA levels can activate toll-like receptor 4 on the surface of macrophages and adipocytes, thereby inducing an inflammatory response in the fatty liver (Yuan, 2001). Activated Kupffer cells in the liver can secrete large amounts of cytokines, including TNF- $\alpha$, IL-1, IL-6, and IL-8 (Rutkowski et al., 2009). TNF- $\alpha$ promotes FFA secretion in peripheral tissue and fatty acid synthesis in the liver; IL- 1 and IL- 6 can likewise hinder the transport and secretion of TGs (Navasa et al., 1998).

The FLS can damage hepatocyte mitochondria and thus influence $\beta$-oxidation of fatty acids (Wei et al., 2008). Moreover, peroxisome proliferator-activated receptors (PPARs), which regulate $\beta$-oxidation and energy metabolism, have a close relationship with FLS (Rao and Reddy, 2004; Zhou et al., 2008). Previous studies have shown that activated PPARs can form heterodimers with the nuclear retinoid $\mathrm{X}$ receptor and regulate the transcription of targeted proteins (fatty acid-binding proteins, LPL, phosphoenolpyruvate carboxykinase, stearoyl-coenzyme A desaturase, and the $\beta$-oxidation enzyme system) by binding to the PPAR response element (Hwang et al., 1997; Uppenberg et al., 1999). Overexpression of $\operatorname{PPAR} \delta$ in brown adipose tissue of mice upregulates the

Abbreviations: ACC, acetyl coenzyme A synthetase; CON, control group; E2, estrogen; FAS, fatty acid synthase; FAT, fatty acid transporter; FFAs, free fatty acids; FLS, fatty liver syndrome; GEN, genistein; GnRH, gonadotropin-releasing hormone; GPT, glutamic-pyruvic transaminase; HGE, high-genistein; HELC, high-energy and low-choline; IL, interleukin; LCFAs, long-chain fatty acids; LGE, low-genistein; LPL, lipoprotein lipase; LSFAs, long-chain saturated fatty acids; LXR $\alpha$, liver X receptor alpha; MUFAs, monounsaturated fatty acids; NAFLD, nonalcoholic fatty liver disease; PPARs, peroxisome proliferator-activated receptors; PUFAs, polyunsaturated fatty acids; SREBP1c, sterol regulatory element-binding protein 1; TC, total cholesterol; TG, triglyceride; TNF- $\alpha$, tumor necrosis factor alpha. transcriptional levels of genes related to TG hydrolysis, fatty acid oxidation, and uncoupled oxidative phosphorylation, including acyl-coenzyme A oxidase, muscle carnitine palmityl transferase-1, long-chain and very long-chain acyl-coenzyme A dehydrogenase, and uncoupling proteins (Wang et al., 2003).

Genistein is a type of isoflavone (ISO) widely found in leguminous plants, especially in soya bean and its products. This ISO is structurally similar to E2, allowing it to bind to the E2 receptor. GEN is considered a safe environmental E2. The average human dietary intake of GEN is $2 \mathrm{mg} / \mathrm{kg}$ body weight/day (Setchell et al., 1998). Studies have revealed beneficial effects of ISO with regard to hypercholesterolemia, obesity, diabetes mellitus, and menopausal symptoms (Mazur et al., 1998; Merzdemlow et al., 2000; Hirota et al., 2010; Khan et al., 2011; Kurita et al., 2016). The polyhydroxyphenol nature of GEN enables it to eliminate a variety of reactive oxygen species (ROS), thereby reducing oxidative damage in the skeletal muscle of broilers (Jiang et al., 2007). However, ISO metabolism and sensitivity varies among animals. Significant differences are noted in the amount of GEN in the livers of old hens and male broiler chickens after GEN treatment (Stevenson et al., 2014). Dietary GEN at a dose of $800 \mathrm{mg} / \mathrm{kg}$ feed has been reported to significantly increase the laying performance of quails (Akdemir and Sahin, 2009). Moreover, adding GEN to the diet of hamsters can markedly relieve oxidative stress caused by lipid peroxidation and lower the serum LPL level (Fang et al., 2004). GEN can activate $\operatorname{PPAR} \alpha$ and PPAR $\gamma$ simultaneously and promote $\beta$-oxidation (Mezei et al., 2003). Several studies have indicated that ISO can exert anti-inflammatory activity. Dietary GEN at a dose of $20-80 \mathrm{mg} / \mathrm{kg}$ feed improves the growth performance and immunity of broiler chickens (Chun et al., 2008; Gudbrandsen et al., 2009). LCFAs can induce lipid peroxidation and hepatocyte damage through interactions among TNF- $\alpha$, PPAR $\alpha$, CYP2E1, leptin, and UCP2 (Kohjima et al., 2005). However, PUFAs exert a negative regulatory effect on pathogenesis of the fatty liver. PUFAs can inhibit the expression of pro-inflammatory factors and increase endogenous anti-inflammatory factors (Stulnig, 2003). n-3 PUFAs were reported to decrease fat accumulation in the livers of both obese rats and patients with nonalcoholic fatty liver disease (Capanni et al., 2006). It is pivotal to investigate the effects of GEN on the fatty acid profile in the liver of hens with FLS. Therefore, with this study, we aim to clarify the molecular mechanism whereby dietary GEN relieves FLS in laying hens through interactions among lipid metabolism, inflammatory response, and antioxidation. 


\section{MATERIALS AND METHODS}

\section{Birds and Husbandry}

The animal experimental procedures were approved by the China Agriculture University Animal Care and Use Committee, Beijing, China. A total of 405 80-week-old JINGFEN 1 laying hens of similar weight $(1870.9 \pm 202.1 \mathrm{~g})$ were randomly allotted to three treatments, with nine replicates of 15 birds each. The hens were raised in ladder cages with three birds each. During the two-week acclimation period, hens were exchanged between the pens to form replicates of similar initial mean BW and egg production. The formal experimental period was from 82 to 90 weeks of age. According to the Nutrient Requirements of Poultry (NRC, 1994) and Zhang et al. (2018), the control group (CON) was fed a HELC basal diet to establish a pathological fatty liver model (Table 1).

TABLE 1 | Composition and nutrient levels of diet.

\begin{tabular}{|c|c|}
\hline Ingredient & $\%$ of diet, weeks $80-90$ \\
\hline Corn & 65 \\
\hline Soybean meal & 3.5 \\
\hline Corn protein & 3.917 \\
\hline Gossypol-free cottonseed protein & 10 \\
\hline Limestone & 8.5 \\
\hline Soybean oil & 2.011 \\
\hline Dicalcium phosphate & 1.715 \\
\hline $\mathrm{NaCl}$ & 0.35 \\
\hline Zeolite & 2 \\
\hline Trace mineral premix ${ }^{a}$ & 0.3 \\
\hline Choline chloride (50\%) & 0.12 \\
\hline Mycotoxin adsorbent & 0.1 \\
\hline DL-methionine & 0.09 \\
\hline Vitamin premix ${ }^{b}$ & 0.035 \\
\hline Santoquin & 0.03 \\
\hline Phytase & 0.015 \\
\hline $4 \%$ flavomycin & 0.015 \\
\hline Lysine.HCl (8\%) & 0.258 \\
\hline Threonine & 0.024 \\
\hline Tryptophan & 0.085 \\
\hline Wheat middlings & 1.935 \\
\hline Total & 100 \\
\hline Available metabolic energy (MC/kg) & 2.91 \\
\hline Crude protein (\%) & 16.1 \\
\hline Calcium (\%) & 3.5 \\
\hline Total phosphorus (\%) & 0.6 \\
\hline Available phosphorus (\%) & 0.48 \\
\hline Methionine (\%) & 0.35 \\
\hline Lysine (\%) & 0.75 \\
\hline Met + Cys (\%) & 0.6 \\
\hline Threonine (\%) & 0.54 \\
\hline Tryptophan (\%) & 0.16 \\
\hline \multicolumn{2}{|c|}{$\begin{array}{l}{ }^{2} \text { The trace mineral premix supplied the following per kilogram of complete feed: } \\
\text { copper, } 8 \mathrm{mg} \text {; zinc, } 75 \mathrm{mg} \text {; iron, } 80 \mathrm{mg} \text {; manganese, } 100 \mathrm{mg} \text {; selenium, } 0.15 \mathrm{mg} \text {; } \\
\text { iodine, } 0.35 \mathrm{mg} \text {. 'bThe vitamin premix supplied the following per kilogram of } \\
\text { complete feed: vitamin A, } 12,500 \mathrm{U} \text {; vitamin D3, 2,500 IU; vitamin K3, } 2.65 \mathrm{mg} \text {; } \\
\text { vitamin B1, } 2 \mathrm{mg} \text {; vitamin B2, } 6 \mathrm{mg} \text {; vitamin B12, } 0.025 \mathrm{mg} \text {; vitamin E, } 30 \mathrm{IU} \text {; biotin, } \\
0.0325 \mathrm{mg} \text {; folic acid, } 1.25 \mathrm{mg} \text {; pantothenic acid, } 12 \mathrm{mg} \text {; niacin, } 50 \mathrm{mg} \text {. }\end{array}$} \\
\hline
\end{tabular}

The LGE and HGE groups were fed a diet identical to that of the CON group, but the feed was supplemented with GEN at 40 and $400 \mathrm{mg} / \mathrm{kg}$ diet, respectively. The GEN was a synthetic product with $99.9 \%$ purity from Kai Meng Co. (Xi An, China) Chemical Plant. All groups were fed the experimental diets for 64 days. The experimental diets and water were provided ad libitum. Eggs were collected daily, and the weight and number of all the eggs produced were determined for each replicate. Food intake was recorded at 1 -week intervals. The room temperature was set at $25 \pm 3^{\circ} \mathrm{C}$, and the light was controlled on a light:dark cycle of 16:8 h. All procedures, as well as the care, housing, and handling of the animals, were conducted according to accepted commercial management practices. The animal experiment was conducted in the China Agricultural University Poultry Facility (Zhuozhou, China).

At 90 weeks of age, two chicks per replicate, with body weights close to the average, were selected after $10 \mathrm{~h}$ of feed deprivation. One blood sample was collected from the wing vein of each chick in vacuum blood collection tubes. The serum was separated out by centrifugation at $3000 \times g$ for $15 \mathrm{~min}$ and stored at $-20{ }^{\circ} \mathrm{C}$ until it was used for the measurement of hormones and biochemical indices. Additional blood samples were collected from the wing vein into vacuum blood collection tubes (with EDTA) for routine blood tests. Then, two chickens from each replicate were killed by decapitation. The liver, the spleen, and the abdominal fat were measured to calculate the organ indices. Tissue samples from those three locations were collected, frozen in liquid nitrogen, and kept in a freezer $\left(-80^{\circ} \mathrm{C}\right)$ for measurements of gene expression, antioxidative indices, and LCFAs.

\section{Radioimmunoassay for Serum Hormone Concentrations}

The serum levels of E2 were measured using commercial double-antibody radioimmunoassay kits purchased from Shanghai Institute of Biological Products. The interassay coefficient of variation was $10 \%$.

\section{Determination of Antioxidant Enzyme Activity and Malondialdehyde (MDA) Levels}

The formation of MDA was used as an indicator of lipid peroxidation via the thiobarbituric acid assay (MDA detection kit A003, Jiancheng Bioengineering Institute, Nanjing). Glutathione peroxidase (GSH-Px), catalase (CAT), and superoxide dismutase (SOD) activity were determined using kits from Nanjing Jiancheng Bioengineering Institute (CAT detection kit A0071-1, SOD detection kit A001-3, GSH-Px detection kit A005). The protein concentrations of the samples were measured using the Bradford method (Bradford, 1976).

\section{Serum Biochemical Indices and Routine Blood Tests}

Serum biochemical indices, including GPT, glutamic-oxaloacetic transaminase (GOT) and creatinine (CRE), as well as TGs, FFAs, $\mathrm{TC}$, and very low-density lipoprotein (VLDL) were measured 
using assay kits (Unicel DXC 800, CA, United States). VLDL was examined using commercially available colorimetric diagnostic kits (H249, Nanjing Jiancheng Bioengineering Institute, China). Routine blood tests were conducted for red blood cells (RBC), hematocrit (HCT) and hemoglobin (HGB), platelets (PLT), procalcitonin (PCT), LUC (large unstained cells), basophils (BASO), and white blood cells (WBC) using assay kits (Sysmex KX-21 N automatic blood analyzer, Kobe, Japan).

\section{Pathological Observation}

Tissue blocks were fixed in $10 \%$ formalin. After $72 \mathrm{~h}$, liver samples of suitable size were taken for routine paraffin embedding and hematoxylin and eosin (HE) staining. Light microscopy (LEICA DMI6000 B) was used to observe and record histopathological changes.

\section{Serum Antibody and Immunoglobulin Levels}

The serum antibody titers against Newcastle disease (ND) and four avian influenza viruses (RE-6, RE-7, RE-8, and H9) were determined using a commercial ELISA kit (IDEXX Laboratories Inc., Westbrook, ME, United States) according to the manufacturer's protocol.

\section{Long-Chain Fatty Acid (LCFA) Analysis}

We first used a vacuum freeze-drying machine (CA301/801, SANYO, Japan) to dry the liver samples. Then, lipids were extracted for the subsequent LCFA analysis according to the method of Bligh and Dyer (Bligh and Dyer, 1959). The methyl esters of the LCFAs from the lipid extract were transesterified with hydrochloric acid $(\mathrm{HCl})$ in methanol according to the method described by Ichihara and Fukubayashi (2010). LCFAs were quantified using an Agilent Technologies 7890A Gas Chromatograph (Santa Clara, CA, United States) with a flame ionization detector. The LCFAs were separated on a 112-88A7 HP-88 capillary column $(100 \mathrm{~m} \times 0.25 \mathrm{~mm}, 0.2 \mu \mathrm{m})$ using helium $(\mathrm{He})$ as a carrier gas at a flow rate of $105 \mathrm{~mL} / \mathrm{min}$. The samples were injected at a starting oven temperature of $175^{\circ} \mathrm{C}$; the injector temperature was $250^{\circ} \mathrm{C}$, and the detector temperature was $280^{\circ} \mathrm{C}$. The oven temperature was programmed to increase from 175 to $220^{\circ} \mathrm{C}$. Fatty acids were identified by their retention time compared with reference fatty acid standards (Supelco, FAME Mix, Sigma-Aldrich) and are expressed in milligrams per gram of total fatty acids in the liver.

\section{Quantitative Reverse Transcription Polymerase Chain Reaction (qRT-PCR) Analysis}

Total RNA was isolated from liver samples using TRIzol reagent (Invitrogen, Carlsbad, CA, United States) according to the manufacturer's protocol. cDNA synthesis was performed using a PrimeScript RT reagent kit with gDNA Eraser (TaKaRa, Dalian, Liaoning, China) according to the manufacturer's instructions. One-step real-time RT-PCR was performed using
SYBR Premix Ex Taq ${ }^{\mathrm{TM}}$ (TaKaRa, Dalian, Liaoning, China) in a real-time PCR machine (ABI7500; Applied Biosystems, Carlsbad, CA, United States) following the manufacturer's guidelines. The primer pairs used are shown in Table 2. The housekeeping gene $\beta$-actin was utilized as an internal control. Relative mRNA expression levels of each target gene were normalized to the control using the $2^{-\Delta \Delta C T}$ method. As previously described, total RNA was treated with deoxyribonuclease, reverse transcribed, and amplified by qPCR with oligonucleotide primers specific to

TABLE 2 | Primers used for quantitative real-time PCR analysis.

\begin{tabular}{|c|c|c|}
\hline Gen name & $5^{\prime}$ primer & Prod side \\
\hline \multirow[t]{2}{*}{ SREBP1c } & F: GCCCTCTGTGCCTITGTCTTC & 122 \\
\hline & R: ACTCAGCCATGATGCTTCTTC & \\
\hline \multirow[t]{2}{*}{ FAS } & F: TGGACGAGTGTATGAGATGTCG & 138 \\
\hline & R: CGCAATGTTCACACCGAGA & \\
\hline \multirow[t]{2}{*}{$\operatorname{LXR} \alpha$} & F: CAAAGGGAATGAATGAGC & 145 \\
\hline & R: AGCCGAAGGGCAAACAC & \\
\hline \multirow[t]{2}{*}{$\operatorname{PPAR} \alpha$} & F: TCCTTCCCGCTGACCAAA & 112 \\
\hline & R: TCCTGCACTGCCTCCACA & \\
\hline \multirow[t]{2}{*}{ PPAR $\gamma$} & F: CGAGGAGTCTTCCAACTC & 135 \\
\hline & R: CCTGATGGCATTATGTGA & \\
\hline \multirow[t]{2}{*}{ PPAR $\delta$} & F:TGAATGACCAAGTGACTCTGCTGAAG & 320 \\
\hline & R: CAGTGCTCGGAGGATGTTGTCTTG & \\
\hline \multirow[t]{2}{*}{ АCOT8 } & F: CCACTCGCTTCACTGCTACTTCG & 322 \\
\hline & R: TGGCACATCTTCAGCTTGGATCTTG & \\
\hline \multirow[t]{2}{*}{ FAT } & F: ACTGGGAAGGTTACTGCGATT & 119 \\
\hline & R: TCACGGTCTTACTGGTCTGGT & \\
\hline \multirow[t]{2}{*}{ ACC } & F: AATGGCAGCTTTGGAGGTGT & 114 \\
\hline & R: TCTGTTTGGGTGGGAGGTG & \\
\hline \multirow[t]{2}{*}{ HMGCoAS } & F: AGCAAATGGTGTITCAGTGG & 117 \\
\hline & R: AGAAGCAAGGCAACCGTAGAC & \\
\hline \multirow[t]{2}{*}{ ACAD8 } & F: GATTGTCACGTCTCGATACCTCCATC & 138 \\
\hline & R: CCTGTGCCTCTGTTCCTCATTGC & \\
\hline \multirow[t]{2}{*}{ ACADs } & F: GCTCTGGACTGTGCTGTGGATTATG & 284 \\
\hline & R: CGTTCTGCTGGCATCTCTGTCAC & \\
\hline \multirow[t]{2}{*}{ Wnt5a } & F: ACTTGGCAGCACAATGGCTT & 96 \\
\hline & R: GACCACCAAGAGCTGGCTTC & \\
\hline \multirow[t]{2}{*}{$\mathrm{IL}-1 \beta$} & F: ACTGGGCATCAAGGGCTA & 104 \\
\hline & B: GGTAGAAGATGAAGCGGGTC & \\
\hline \multirow[t]{2}{*}{ IL-8 } & F: ATGAACGGCAAGCTTGGAGCTG & 122 \\
\hline & R: TCCAAGCACCTCTCTTCCATCC & \\
\hline \multirow[t]{2}{*}{$N F-\kappa B$} & F: GTGTGAAGAAACGGGAACTG & 118 \\
\hline & R: GGCACGGTTGTCATAGATGG & \\
\hline \multirow[t]{2}{*}{ AFABP } & F: CAGCATCAATGGTGATGT & 134 \\
\hline & R: ACAGTCTCTITGCCATCC & \\
\hline \multirow[t]{2}{*}{ TNF- $\alpha$} & F: GAGCGTTGACTTGGCTGTC & 121 \\
\hline & R: AAGCAACAACCAGCTATGCAC & \\
\hline \multirow[t]{2}{*}{$\mathrm{IFN}-\gamma$} & F: AGCTGACGGTGGACCTCA & 116 \\
\hline & R: GGCTTTGCGCTGGATTC & \\
\hline \multirow[t]{2}{*}{ TCF3 } & F: TGCTCCACAACCATGTCACACTTC & 146 \\
\hline & R: TGTTCTCCTCATCCTCCTTCTCTTCC & \\
\hline \multirow[t]{2}{*}{ GAPDH } & F:TGCTGCCCAGAACATCATCC & 120 \\
\hline & R:ACGGCAGGTCAGGTCAACAA & \\
\hline
\end{tabular}

Frepresent forward, $R$ represent reward. 
chickens. The net intensity ratios of target genes to GAPDH were used to represent the relative levels of target gene expression. The means of two replicates were used for statistical analysis.

\section{Statistical Analysis}

The results were expressed as the mean \pm SD or mean \pm SEM (for gene expression), and differences were considered significant when $P<0.05$ as tested by ANOVA in SPSS 11.0 for Windows.

\section{RESULTS}

\section{Assessment of Production Performance}

In the present study, dietary GEN at the $40 \mathrm{mg} / \mathrm{kg}$ dose increased the egg-laying rates of laying hens at weeks 1, 4, 6, 7, and 8. However, the $400 \mathrm{mg} / \mathrm{kg}$ supplementation level decreased the egg-laying rates during the whole experimental period $(P<0.05$, Figure 1A). As shown in Figure 1B, the egg weight of hens in the LGE group was lower than that of the CON group, but the difference was not significant. In addition, High-dose GEN treatment increased feed/egg ratio compared with other two groups $(P=0.063$, Table 3). Dietary GEN had no significant effects on the feed intake of laying hens in this experiment (Table 3).

\section{Levels of Hormones Involved in the Hypothalamic-Pituitary-Gonadal (HPG) Axis}

The effects of GEN on the level of E2 in the serum of chickens are presented in Table 4 . The level of E2 was significantly higher in the LGE group than in the CON group $(P<0.05)$, while the $400 \mathrm{mg} / \mathrm{kg}$ supplementation level had no significant effects on E2. Reproductive performance is mediated by the HPG axis; thus, we measured the mRNA expression of HPG axis-related genes using qPCR. The transcriptional level of GnRH in the hypothalamus was significantly upregulated in the LGE group $(P<0.05)$ compared with that in the CON group; the $400 \mathrm{mg} / \mathrm{kg}$ supplementation significantly downregulated $\mathrm{GnRH}$ mRNA expression (Figure 3, $P<0.05$ ), which might be directly responsible for the different effects of the two doses on the laying performance.

\section{Hepatic Scores, Statistics, and Organ Indices}

As is shown in Figure 2a, we classified the fatty liver severity into six levels according to the hepatic clinical scores. We defined levels 3 to 6 as the FLS. As shown in Table 4, the mean hepatic clinical score of the hens fed the control HELC diet was 4, and the livers of the CON group were enlarged and appeared yellowish or yellowish brown in color. The livers presented severe symptoms including rupture, bleeding, and friable texture.
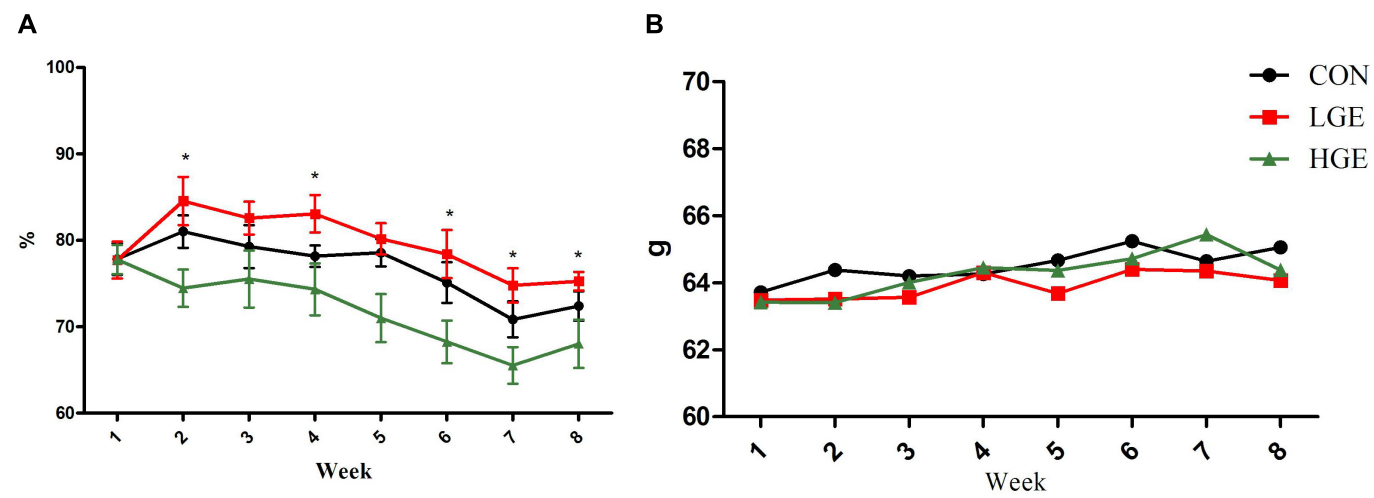

FIGURE 1 | (A,B) Represent the effects of GEN supplementation on the egg-laying rate and average egg weight of laying hens during the late egg-laying period, respectively. Mean values with $\left(^{*}\right)$ differ significantly between the control and GEN-treated hens $(n=9$ replicates).

TABLE 3 | Effect of dietary GEN on feed/egg ratio, daily feed intake, organ indices, and liver scores in hens.

\begin{tabular}{|c|c|c|c|c|}
\hline Treatment & CON & LGE & HGE & $P$-value \\
\hline Daily feed intake (g) & $103.4 \pm 4.7$ & $100.6 \pm 4.3$ & $104.0 \pm 3.2$ & 0.187 \\
\hline Feed/egg ratio & $2.14 \pm 0.11$ & $2.09 \pm 0.03$ & $2.25 \pm 0.06$ & 0.063 \\
\hline Abdominal fat rate (\%) & $6.85 \pm 2.25 a$ & $4.43 \pm 1.25 b$ & $4.58 \pm 1.78 b$ & 0.001 \\
\hline Liver index (\%) & $2.40 \pm 0.28 a$ & $2.18 \pm 0.24 b$ & $2.15 \pm 0.25 b$ & 0.026 \\
\hline Spleen index (\%) & $0.104 \pm 0.025$ & $0.092 \pm 0.023$ & $0.084 \pm 0.016$ & 0.016 \\
\hline Clinical score of liver & $4.00 \pm 0.24 a$ & $2.10 \pm 0.42 b$ & $2.51 \pm 0.53 b$ & $<0.001$ \\
\hline Pathological score of liver & $2.4 \pm 0.5 a$ & $0.3 \pm 0.3 b$ & $0.4 \pm 0.4 b$ & $<0.001$ \\
\hline
\end{tabular}

Data represent the mean $\pm S D$ of values ( $n=9$ replicates, 2 samples each replicate). Mean values without a common identifier (a and b) differ significantly ( $P<0.05)$. 
TABLE 4 | Effect of dietary GEN on the serum metabolic indices and routine blood indices of hens. ${ }^{a}$

\begin{tabular}{|c|c|c|c|c|}
\hline Treatment & CON & LGE & HGE & $P$-value \\
\hline \multicolumn{5}{|c|}{ Serum metabolic indices ${ }^{1}$} \\
\hline GPT (U/L) & $4.79 \pm 1.12$ & $3.83 \pm 0.76$ & $4.16 \pm 0.74$ & 0.069 \\
\hline GOT (U/L) & $179.2 \pm 42.4$ & $151.3 \pm 38.1$ & $163.8 \pm 25.8$ & 0.198 \\
\hline TC (mmol/L) & $4.40 \pm 1.70 \mathrm{a}$ & $2.63 \pm 0.26 b$ & $2.65 \pm 0.63 b$ & 0.012 \\
\hline TG (mmol/L) & $17.0 \pm 3.8 \mathrm{a}$ & $11.1 \pm 1.0 b$ & $11.7 \pm 2.3 b$ & 0.001 \\
\hline $\mathrm{CRE}(\mu \mathrm{mol} / \mathrm{L})$ & $110.6 \pm 22.2 a$ & $86.4 \pm 5.9 b$ & $90.0 \pm 9.4 b$ & 0.015 \\
\hline FFAs ( $\mu \mathrm{mol} / \mathrm{L})$ & $410.3 \pm 28.5$ & $388.0 \pm 11.5$ & $385.3 \pm 16.0$ & 0.070 \\
\hline E2 (pg/mL) & $59.46 \pm 8.30 b$ & $73.26 \pm 6.91 a$ & $64.01 \pm 7.23 b$ & 0.005 \\
\hline VLDL (mmol/L) & $1.80 \pm 0.22 b$ & $2.14 \pm 0.30 a$ & $2.07 \pm 0.29 a$ & 0.031 \\
\hline \multicolumn{5}{|l|}{ Routine blood indices ${ }^{2}$} \\
\hline RBC $\left(\times 10^{12}\right.$ cells $\left./ L\right)$ & $2.54 \pm 0.23 b$ & $2.62 \pm 0.21 \mathrm{ab}$ & $2.70 \pm 0.14 a$ & 0.041 \\
\hline HGB (g/L) & $102.4 \pm 10.6$ & $107.2 \pm 5.9$ & $107.1 \pm 8.0$ & 0.121 \\
\hline PLT $\left(\times 10^{9}\right.$ cells/L) & $98.4 \pm 22.6$ & $111.4 \pm 34.2$ & $124.3 \pm 43.2$ & 0.053 \\
\hline LUC (\%) & $1.84 \pm 1.73$ & $1.23 \pm 0.85$ & $1.05 \pm 0.52$ & 0.051 \\
\hline BASO (\%) & $0.74 \pm 0.33 b$ & $1.06 \pm 0.52 a$ & $0.75 \pm 0.38 b$ & 0.025 \\
\hline WBC (×109 cells/L) & $44.8 \pm 11.8$ & $48.4 \pm 12.2$ & $53.0 \pm 9.1$ & 0.070 \\
\hline
\end{tabular}

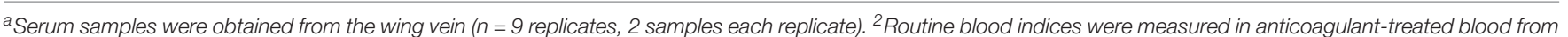

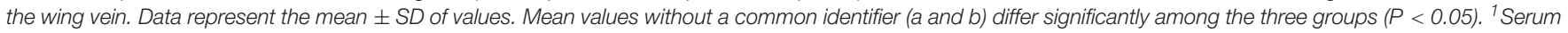

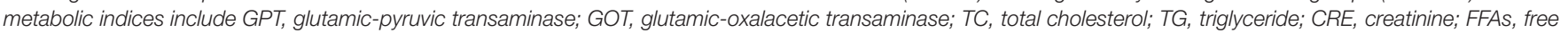

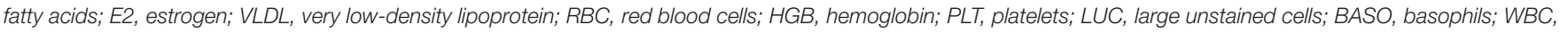
white blood cells.

When the tissue was cut with a knife, fat drops clung to the surface of the knife. There were large amounts of fat deposited in the abdomen, subcutaneous tissue, pericardium, stomach, and mesentery. The clinical categorization scheme used for assessing fatty liver is shown in Table 5. The hepatic clinical scores of the LGE and HGE group were significantly lower than that of the CON group $(P<0.05)$, indicating the favorable, anti-FLS effect of GEN. In terms of histological changes, we observed hepatocyte tumefaction and focal necrosis in the CON group (Figure 2b). The hepatocytes of the CON group contained fat vacuoles of various sizes, which pushed the nuclei aside. In addition, the structures of the hepatic sinusoids were not clear. We also observed some inflammatory cell infiltration around the blood vessels. The hepatic pathological scores of the LGE and HGE groups were significantly decreased compared with those of the CON group. The sizes and shapes of the cells were normal; we did not detect any signs of hepatocyte tumefaction, granule denaturation or vacuolation. Furthermore, GEN treatment decreased the abdominal fat rate and the liver and spleen organ indices of laying hens during the late egg-laying period (Table 3, $P<0.05$ ).

\section{Serum Metabolic Indices and Routine Blood Tests}

The changes of serum metabolic indices are shown in Table 4. The serum levels of TC $(P<0.05)$, TG $(P<0.05)$, and FFA $(P=0.07)$ in LGE and HGE group were significantly reduced compared with the CON group, indicating GEN treatment improved the disorder of lipid metabolism. The high-GEN treatment significantly decreased the serum GPT $(P=0.069)$ and CRE levels $(P<0.05)$, indicating that GEN treatment improved the liver and kidney functions. The function of VLDL is to transport TGs and TC to tissues. GEN treatment significantly increased the level of VLDL in the serum of laying hens $(P<0.05)$. RBC $(P<0.05)$, PLT $(P=0.053)$, PCT $(P<0.05)$, and WBC $(P=0.070)$ in the venous blood of HGE group was increased compared with levels in the CON group. The number of BASO in the blood of LGE group was increased compared with that in the CON group $(P<0.05)$. Additionally, GEN treatment reduced the number of LUC in blood of hens, indicating that GEN could reducing inflammatory reaction in the FLS hens.

\section{Antibody Titer in the Serum}

As shown in Table 6, adding GEN to the diet of FLS hens during the late egg-laying period had no significant effect on the serum antibody titer.

\section{Measurement of Hepatic Antioxidant Indices}

The effects of GEN on the antioxidant enzyme activity and MDA levels in the livers of the hens are shown in Table 7. Dietary GEN significantly decreased the level of MDA, a lipid peroxidation product, in the livers of FLS hens $(P<0.05)$. The activities of SOD in the livers of the LGE and HGE groups were increased by $10.58 \%(P=0.184)$ and $37.35 \%(P<0.01)$, respectively, compared with the activity in the CON group. Thus, dietary GEN enhanced the antioxidant capacity of FLS hens. However, GEN had no significant effects on the activity of hepatic CAT or GSH-Px.

\section{Measurement of Liver Fatty Acid Profiles}

As shown in Table 8, GEN treatment significantly decreased the total LSFA level $(P<0.05)$ and increased the C22:0 level $(P<0.01)$ compared with those of the CON group. GEN treatment increased the total n-3 family LCFAs in the livers of the 

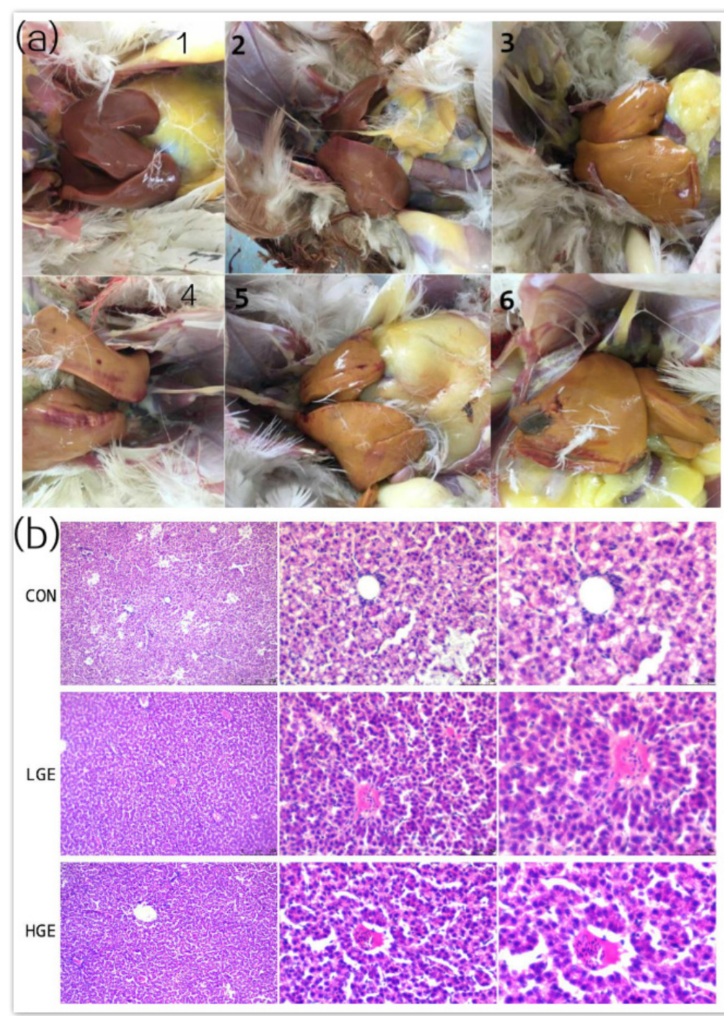

FIGURE 2 | (a) Clinical scores for chicken livers were divided into six levels representing different degrees of FLS. (b) Chicken livers were stained with HE, viewed under a microscope $(100 \times, 400 \times$, and $600 \times)$, and assigned pathological scores representing the degree of FLS. The categorization scheme is shown in Table 5.

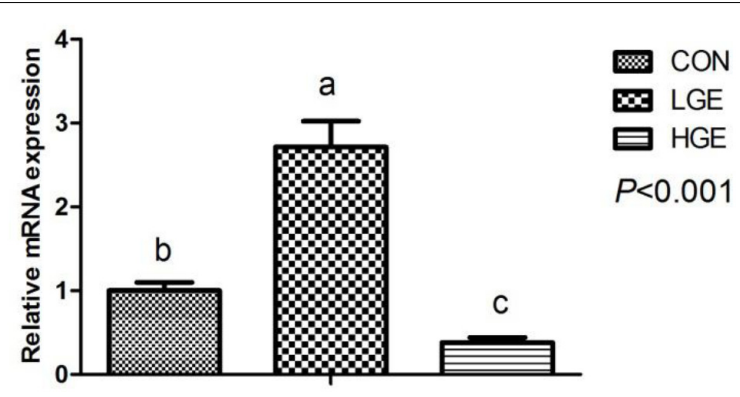

FIGURE 3 | Effect of dietary GEN on GnRH mRNA expression in the hen hypothalamus ( $n=8$ replicates). Data represent the mean \pm SEM of the values. Mean values without a common identifier ( $a, b$, and c) differ significantly among the three groups $(P<0.05)$.

HLS hens $(P<0.05)$ and decreased the C18:2n6c $(P=0.001)$ and C18:3n6 levels $(P<0.05)$. However, C18:3n3 was significantly less abundant in the livers of the LGE and HGE groups than in those of the CON group $(P<0.01)$. In addition, the levels of C20:3n6 and C20:4n6 in the livers of LGE $(P<0.05)$ and HGE $(P<0.01)$ hens were increased after GEN treatment compared with the levels in the CON group. On the whole, dietary GEN significantly decreased LCFAs (saturated, n-6 family, MUFAs and PUFAs; $P<0.01$ for each category).

\section{The Effects of GEN on Metabolism-Regulating Factors in the Liver and Abdominal Fat}

The liver is the main site of fat metabolism in poultry. The expression levels of genes relating to lipid metabolism in the chicken liver (Figure 4A) were examined. Dietary GEN significantly upregulated PPAR $\alpha$ and PPAR $\delta$ mRNA expression $(P<0.05)$. LXR $\alpha$ and SREBP1c are downstream signaling proteins of PPARs and are involved in fatty acid and cholesterol anabolism. The transcriptional levels of the genes encoding LXR $\alpha$ and SREBP1c were significantly reduced by both high- and low-dose GEN treatment with the downregulated expression of ACC, FAS, and 3-hydroxy-3-methylglutaryl-coenzyme A synthase (HMGCoAS). Acyl-CoA thioesterase (ACOT) 8 and acyl-CoA dehydrogenase (ACAD) 8, which are involved in $\beta$-oxidation, were more abundantly transcribed in the livers of the LGE and HGE groups than in those of the CON group $(P<0.05)$. GEN treatment and $400 \mathrm{mg} / \mathrm{kg}$ diet significantly upregulated the mRNA expression of ACADs in the liver compared with the expression in the CON group $(P<0.05)$. Additionally, GEN treatment reduced the transcriptional level of WNT5a and FAT in the liver $(P<0.05)$. Abdominal fat is one of the storage sites for lipids in poultry, especially when FLS occurs. PPARG is the gene encoding PPAR $\gamma$, which promotes adipocyte differentiation and fat deposition. One of the downstream target genes regulated by PPAR $\gamma$ is adipocyte fatty acid-binding protein (AFABP). PCR results showed that the mRNA expression levels of PPARD and AFABP were significantly higher in the abdominal fat of the LGE and HGE groups than in those of the CON group $(P<0.05$, Figure 4B).

\section{The Effects of GEN on Immunity-Regulating Factors in the Liver and Abdominal Fat}

In addition to hepatocytes, the liver tissue also contains sinusoidal endothelial cells, stellate cells, dendritic cells, Kupffer cells, and lymphocytes. These cells secrete a series of cytokines, which play an important role in immune regulation. The spleen is the main peripheral immune organ of poultry. As shown in Figure 5A, NF- $\kappa$ B, TNF- $\alpha$, IL- 8 , and IL- $1 \beta$ mRNA expression was significantly upregulated in the livers and spleens of the LGE and HGE groups compared to expression in those of the CON group $(P<0.05)$. The results showed that GEN treatment significantly increased the transcription of TCF3 in the liver and spleen (Figure 5B, $P<0.05$ ). Additionally, GEN treatment significantly increased the transcriptional levels of PPAR $\delta$ and IFN $\gamma$ (Figure 5B, $P<0.05)$.

\section{DISCUSSION}

The FLS has been reported to be one of the most fatal non-communicable diseases in layers (Mete et al., 2013). FLS 
TABLE 5 | The categorization scheme of pathological scores of fatty liver. $^{\text {a }}$

\begin{tabular}{|c|c|c|c|}
\hline Pathological type & Histopathological changes & Degree & Scores \\
\hline \multirow[t]{5}{*}{ Steatosis } & Indicating the normal state. & None & 0 \\
\hline & The lesion was between 0 and 1 points. & \pm & 0.5 \\
\hline & The fat vacuoles in the liver cells were small and scattered. & Minor lesions + & 1 \\
\hline & The fat vacuoles in the liver cells are larger and wider in range. & Moderate lesions ++ & 2 \\
\hline & $\begin{array}{l}\text { The fat vacuoles are fused into large vacuoles, and the nucleus } \\
\text { is squeezed into the cell membrane. It likes the adipocyte. }\end{array}$ & Severe lesions +++ & 3 \\
\hline
\end{tabular}

aThe pathological scores of fatty liver are divided into five grades (0-3), according to the levels of steatosis.

is characterized by a large amount of fat deposited in the hepatocytes, resulting in fatty liver, liver hemorrhage, and obesity. Choline can bind to fat and prevent the abnormal accumulation of fat in the liver. In the present study, laying hens were fed the HELC diet as their basal diet to establish a model of FLS. Clinicopathological evaluation showed that the livers of layers fed with the HELC diet were pale yellow, friable, and swollen, with hemorrhagic spots and attached fat on the surface. Histopathological analysis demonstrated that the livers of the CON group had the typical FLS features of hepatocyte steatosis and altered hepatocyte shape. FLS has been reported to significantly reduce the egg production and feed intake of layers (Jiang et al., 2013). The antioxidant and estrogenic effects of GEN are stronger than those of other kinds of soybean ISOs. In the present study, $40 \mathrm{mg} / \mathrm{kg}$ GEN treatment significantly increased the laying rate of FSL layers during the late egg-laying period. However, $400 \mathrm{mg} / \mathrm{kg}$ GEN treatment significantly reduced the laying rate. Neither high- nor low-dose GEN supplementation in feed had any significant effect on feed intake or egg weight. Research has shown that an appropriate amount of daidzein, which is a type of ISO, can improve the reproductive performance of female Zhedong White geese by regulating reproductive hormones in the HPG axis (Zhao et al., 2013). In the current study, $40 \mathrm{mg} / \mathrm{kg}$ GEN treatment significantly increased the transcriptional level of GnRH in the hypothalamus of layers, while the same hormone was downregulated by $400 \mathrm{mg} / \mathrm{kg}$ GEN treatment. These effects on GnRH could explain the difference in the reproductive performance of FLS layers after the two levels of GEN treatment. In addition, the negative effects of high-dose GEN might also be due to the inhibition of tyrosine protein kinases and related effects on the physiological state of FLS layers. Studies on rodents also indicate that the effects of GEN on production performance vary with sex, age, endogenous hormone levels, and the GEN dose (Naaz et al., 2003; Penza et al., 2006; Castellano et al., 2011). GEN supplementation also upregulates ESR $\alpha$ and $\operatorname{ESR} \beta$ mRNA expression in the livers of mice fed a high-fat diet (Tang et al., 2015). In the present study, low-dose GEN treatment improved the serum level of E2 in FLS layers, while high-dose GEN had no significant effect on the E2 level. Our work demonstrates for the first time that the effects of high and low doses of GEN on reproductive hormones, leading to significant differences in the production performance of hens with FLS.

Long-chain fatty acids and TGs accumulate in the liver when their synthesis, transport, and catabolism are disordered, which can cause hepatic steatosis (Koteish and Diehl, 2001; Bradbury
TABLE 6 | Effect of dietary GEN on serum antibody titers in hens.

\begin{tabular}{lccccc}
\hline Treatment & ND & RE-6 & RE-7 & RE-8 & H9 \\
\hline CON & $8.9 \pm 0.4$ & $9.8 \pm 0.7$ & $8.4 \pm 0.5$ & $7.1 \pm 1.2$ & $11.4 \pm 0.7$ \\
LGE & $9.4 \pm 0.8$ & $10.0 \pm 1.0$ & $8.6 \pm 0.8$ & $6.7 \pm 0.8$ & $12.0 \pm 0.8$ \\
HGE & $9.0 \pm 1.0$ & $10.1 \pm 0.7$ & $8.4 \pm 1.0$ & $6.0 \pm 1.2$ & $11.9 \pm 1.3$ \\
$P$-value & 0.352 & 0.639 & 0.882 & 0.158 & 0.452 \\
\hline
\end{tabular}

ND, Newcastle disease; RE-6, RE-7, RE-8, and H9 (avian influenza). $n=9$ replicates, 2 samples each replicate. Data represent the mean $\pm S D$ of values.

TABLE 7 | Hepatic antioxidant indices.

\begin{tabular}{lcccc}
\hline Treatment & T-SOD & CAT & GSH-Px & MDA \\
\hline CON & $157.25 \pm 24.35 \mathrm{~b}$ & $18.23 \pm 5.44$ & $22.27 \pm 2.15$ & $0.53 \pm 0.20 \mathrm{a}$ \\
LGE & $173.88 \pm 23.24 \mathrm{~b}$ & $21.98 \pm 4.24$ & $18.78 \pm 3.50$ & $0.33 \pm 0.11 \mathrm{~b}$ \\
HGE & $215.93 \pm 37.45 \mathrm{a}$ & $17.41 \pm 1.38$ & $17.32 \pm 6.15$ & $0.36 \pm 0.09 \mathrm{~b}$ \\
$P$-value & 0.002 & 0.111 & 0.210 & 0.023
\end{tabular}

$\overline{T-S O D}$, total superoxide dismutase (U/mg protein); CAT, catalase (U/mg protein); GSH-PX, glutathione peroxidase (U/mg protein); MDA, malondialdehyde (nmol/mg protein). $n=9$ replicates, 2 samples each replicate. Data represent the mean $\pm S D$ of values. Mean values without a common identifier ( $a$ and $b$ ) differ significantly among the three groups $(P<0.05)$.

and Berk, 2004). In the present study, the content of LCFAs in the livers of FLS hens was significantly reduced by GEN supplementation. Excessive intake and accumulation of MUFAs in the liver contributed to the pathological changes (Øyvind, 1991). We found that dietary GEN significantly reduced the content of MUFAs in the livers of FLS layers. The balance between $n-6$ and $n-3$ PUFAs is essential for maintaining metabolism and immunity in the body (El-Badry et al., 2007). n-3 PUFAs have potent anti-inflammatory, anti-proliferative, and immunoregulatory effects (Chapkin et al., 2007). n-3 PUFAs can inhibit fatty acid synthesis in the liver (Sekiya et al., 2003). In the present study, GEN treatment significantly increased total n-3 PUFAs in the livers of FLS layers, and the levels of C20:5n3 and C22:6n 3 were significantly increased as well. According to a study by Araya et al., the ratio of n- 6 to n-3 PUFAs is significantly increased in the hepatic phospholipid profiles of FLS patients compared with those of normal individuals (Araya et al., 2004). In our study, GEN treatment significantly reduced the content of n- 6 LCFAs and the ratio of $n-6$ to $n-3$ PUFAs in the livers of FLS layers. However, we found that the levels of C20:3n6 and C20:4n6 (arachidonic acid, ARA) were significantly higher in the livers of the LGE and HGE groups than in those 
TABLE 8 | Effects of GEN on long-chain fatty acids and triglyceride in the liver of hens.

\begin{tabular}{|c|c|c|c|c|}
\hline & CON & LGE & HGE & $P$-value \\
\hline \multicolumn{5}{|l|}{ LSFAs } \\
\hline C12:0 & $0.090 \pm 0.016 a$ & $0.042 \pm 0.002 b$ & $0.056 \pm 0.009 b$ & $<0.001$ \\
\hline C14:0 & $2.03 \pm 0.76 a$ & $0.46 \pm 0.23 b$ & $0.79 \pm 0.16 b$ & $<0.001$ \\
\hline C15:0 & $0.20 \pm 0.05 a$ & $0.08 \pm 0.01 b$ & $0.13 \pm 0.03 b$ & 0.001 \\
\hline C16:0 & $119.1 \pm 30.5 a$ & $41.8 \pm 11.8 b$ & $61.0 \pm 7.5 b$ & $<0.001$ \\
\hline C17:0 & $1.11 \pm 0.27 a$ & $0.41 \pm 0.05 b$ & $0.64 \pm 0.13 b$ & $<0.001$ \\
\hline C18:0 & $71.6 \pm 21.5 a$ & $27.8 \pm 4.6 b$ & $39.1 \pm 6.2 b$ & 0.001 \\
\hline C2O:0 & $0.24 \pm 0.05 a$ & $0.18 \pm 0.01 b$ & $0.19 \pm 0.02 b$ & 0.019 \\
\hline $\mathrm{C} 21: 0$ & $0.47 \pm 0.04 b$ & $0.66 \pm 0.08 a$ & $0.55 \pm 0.04 b$ & 0.001 \\
\hline C22:0 & $0.23 \pm 0.03 b$ & $0.4 \pm 0.09 a$ & $0.33 \pm 0.04 a$ & 0.002 \\
\hline C23:0 & $0.06 \pm 0.03 b$ & $0.12 \pm 0.02 a$ & $0.09 \pm 0.01 b$ & 0.006 \\
\hline $\mathrm{C} 24: 0$ & $0.21 \pm 0.04$ & $0.38 \pm 0.09$ & $0.37 \pm 0.08$ & 0.005 \\
\hline \multicolumn{5}{|c|}{ Monounsaturated } \\
\hline C14:1 & $0.15 \pm 0.06 a$ & $0.02 \pm 0.03 b$ & $0.05 \pm 0.02 b$ & 0.001 \\
\hline C16:1 & $6.88 \pm 2.02 a$ & $1.57 \pm 1.00 \mathrm{~b}$ & $2.55 \pm 0.69 b$ & $<0.001$ \\
\hline C18:1n9c & $182.3 \pm 50.2 a$ & $46.4 \pm 18.6 b$ & $75.1 \pm 15.6 b$ & $<0.001$ \\
\hline C2O:1 & $0.53 \pm 0.11 a$ & $0.27 \pm 0.08 b$ & $0.27 \pm 0.06 b$ & 0.001 \\
\hline C22:1n9 & $0.021 \pm 0.012$ & $0.025 \pm 0.002$ & $0.024 \pm 0.003$ & 0.76 \\
\hline C24:1 & $0.16 \pm 0.05$ & $0.21 \pm 0.03$ & $0.18 \pm 0.04$ & 0.183 \\
\hline \multicolumn{5}{|l|}{ n-3 family } \\
\hline C18:3n3 & $1.32 \pm 0.23 a$ & $0.68 \pm 0.28 b$ & $1.14 \pm 0.27 b$ & 0.006 \\
\hline C20:5n3 & $0.00 \pm 0.00$ & $0.01 \pm 0.01$ & $0.01 \pm 0.01$ & 0.287 \\
\hline C22:6n3 & $1.89 \pm 0.39 b$ & $2.73 \pm 0.32 a$ & $2.75 \pm 0.42 a$ & 0.005 \\
\hline \multicolumn{5}{|l|}{ n-6 family } \\
\hline C18:2n6c & $56.7 \pm 11.6 a$ & $29.7 \pm 5.7 b$ & $40.8 \pm 5.7 b$ & 0.001 \\
\hline C18:3n6 & $0.43 \pm 0.21 a$ & $0.16 \pm 0.04 b$ & $0.28 \pm 0.04 b$ & 0.017 \\
\hline C20:3n6 & $0.45 \pm 0.11 b$ & $0.65 \pm 0.04 a$ & $0.65 \pm 0.05 a$ & 0.002 \\
\hline C20:4n6 & $5.62 \pm 1.65 b$ & $8.32 \pm 1.47 a$ & $7.99 \pm 0.68 a$ & 0.015 \\
\hline n-3 family & $3.20 \pm 0.39 b$ & $3.49 \pm 0.15 b$ & $3.90 \pm 0.42 a$ & 0.022 \\
\hline n-6 family & $63.15 \pm 10.23 a$ & $38.86 \pm 4.65 b$ & $49.73 \pm 5.07 b$ & 0.001 \\
\hline n-6:n-3 PUFAs & $18.63 \pm 2.74 a$ & $11.40 \pm 1.24 b$ & $12.88 \pm 2.30 b$ & $<0.001$ \\
\hline LSFAs & $195.33 \pm 52.94 a$ & $72.29 \pm 16.44 b$ & $103.26 \pm 13.11 b$ & $<0.001$ \\
\hline MUFAs & $190.04 \pm 52.01 a$ & $48.45 \pm 19.63 b$ & $78.19 \pm 16.26 b$ & $<0.001$ \\
\hline PUFAs & $65.71 \pm 11.34 a$ & $42.27 \pm 4.74 c$ & $53.63 \pm 4.95 b$ & $<0.001$ \\
\hline LCFAs & $452.2 \pm 113.7 a$ & $163.00 \pm 38.88 b$ & $235.0 \pm 29.4 b$ & $<0.001$ \\
\hline TG & $428.9 \pm 122.8$ & $152.8 \pm 67.7$ & $244.6 \pm 101.4$ & $<0.001$ \\
\hline
\end{tabular}

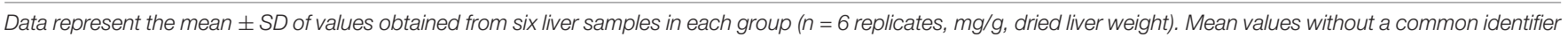
(a and b) differ significantly among the three groups ( $P<0.05)$. LSFAs, long-chain saturated fatty acids. LCFAs, long-chain fatty acids. TG, triglyceride.

of the CON group. Dietary ARA, especially at moderate levels (0.22-0.56\% dry weight), significantly enhanced growth and immune responses and modified the chemical composition of the whole body and liver of the juvenile Japanese seabass (Xu et al., 2010). However, the regulatory mechanism through which GEN influences PUFA levels remains to be studied further. This report is the first to clarify the change in the fatty acid profiles in the livers of laying hens after GEN treatment. Lipid metabolism operates differently in the actively laying hen than in many other animals. Accordingly, high- and low-dose GEN in feed significantly reduced the liver TG content and hepatic scores of layers. Additionally, the levels of TG and FFAs in the serum of hens in the LGE and HGE groups were significantly decreased after GEN treatment compared with the levels in the CON group, which could indicate that the disorder of lipid metabolism was significantly improved. Lipids in poultry plasma are transported into the extrahepatic tissue by binding to VLDL. Studies have shown that mutant apolipoprotein B (ApoB, the structural protein of VLDL) or MTP (responsible for recruitment of TGs) can cause hepatic steatosis by disrupting VLDL assembly (BerriotVaroqueaux et al., 2000; Tanoli et al., 2004). It was found in the present study that dietary GEN significantly increased the serum level of VLDL, which could reduce lipid accumulation in the liver. This result is consistent with the findings that GEN ( $0.5 \mathrm{~g} / \mathrm{kg}$ diet $)$ can alleviate the liver steatosis, cholesterolemia, and obesity symptoms induced by a high-energy diet in mice (Park et al., 2013). The liver and kidneys play important roles in the lipid metabolism of layers, and two relevant parameters (serum GPT and serum CRE) are both decreased by GEN treatment. High- and low-dose GEN treatment showed the 

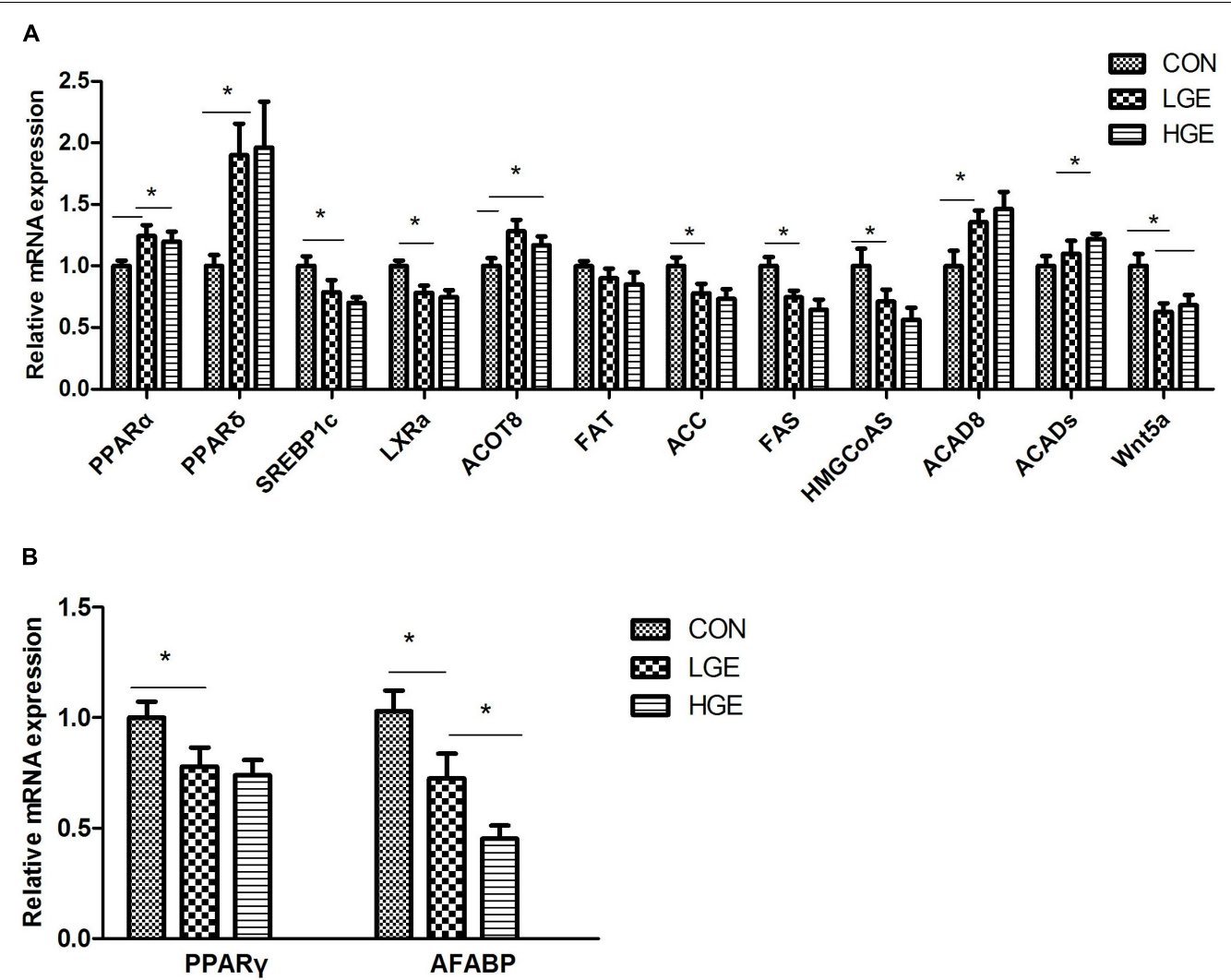

FIGURE 4 | (A,B) Represent the effect of GEN supplementation on the relative mRNA expression of genes related to lipid metabolism in the liver and abdominal fat, respectively; $n=8$ replicates. Data represent the mean \pm SEM of the values. Means with * are significantly different.

same effects on lipid metabolism in FLS layers. However, the effects of the two doses on serum E2, as mentioned above, were significantly different. Therefore, we speculated that the alleviation of FLS by GEN in layers is not regulated only through the E2 signaling pathway.

Genistein has been reported to activate PPARs, which in turn activate the expression of transcription factors related to insulin sensitivity regulation, adipogenesis, and blood pressure (Dang et al., 2003). GEN is reported to upregulate the expression of carnitine acyltransferase (in an ESR-dependent manner) and promote lipolysis in HepG2 cells, and antagonistic effects exist between ESR and PPAR (Bitto et al., 2009). In the present study, high- and low-dose GEN treatment significantly upregulated the transcription levels of PPAR $\alpha$ and PPAR $\delta$ in the livers of supplemented hens compared with controls. PPAR $\alpha$ is involved in the regulation of mitochondrial $\beta$-oxidation and microsomal $\omega$-oxidation, and it inhibits lipogenesis through $\operatorname{LXR} \alpha$ and SREBP1c in the liver. Therefore, PPAR $\alpha$ plays an important role in the occurrence and development of NAFLD (Pyper et al., 2010). LXR $\alpha$ can form a positive feedback loop with SREBP1c and enhance lipogenesis in the liver (Willy et al., 1995). In the present study, high and low doses of GEN significantly downregulated the expression of SREBP1c and $\operatorname{LXR} \alpha$, as well as the target genes ACC, FAS, and FAT. The activation of FAT can promote the uptake of FFAs into the liver, thereby inducing hepatocytic steatosis (Nakamura et al., 2007). Therefore, dietary GEN inhibited fatty acid synthesis in the livers of FLS hens through the PPAR-LXR $\alpha$-SREBP1c-ACC/FAS/FAT pathway. Recent studies have shown that activation of PPAR $\delta$ can reduce the hepatic fat content by increasing glucose catabolism and inhibiting SREBP1c activity in the liver and promoting $\beta$-oxidation in the muscles (Wagner et al., 2011). In the present study, we found that GEN treatment upregulated the expression of ACAD8, ACADs, ACOT8, and FAT. ACADs are a family of mitochondrial flavoenzymes that catalyze dehydrogenation steps of the $\alpha$-and $\beta$-oxidation processes. ACOT8 encodes ACOT 8, which is involved in fatty acid oxidation (Hunt and Alexson, 2002). Studies have shown that ACOT is strongly regulated by PPARs, which can also inhibit fatty acid synthesis (Libertini and Smith, 1978; Miyazawa et al., 1981). Therefore, it is likely that dietary GEN inhibits fatty acid synthesis and enhances $\beta$-oxidation in the livers of layers through the PPAR-ACAD/ACOT and PPAR-LXR $\alpha$-SREBP1c-ACC/FAS/FAT pathways, which would provide a mechanism for the GEN-linked changes in hepatic fatty acid profiles.

Peroxisome proliferator-activated receptor $\gamma$ mainly promotes energy storage and adipocyte differentiation (Vosper et al., 2001). Upregulation of PPAR $\gamma$ has been reported to cause hepatic steatosis (Hoekstra et al., 2009). In the present study, GEN treatment significantly downregulated the transcriptional 


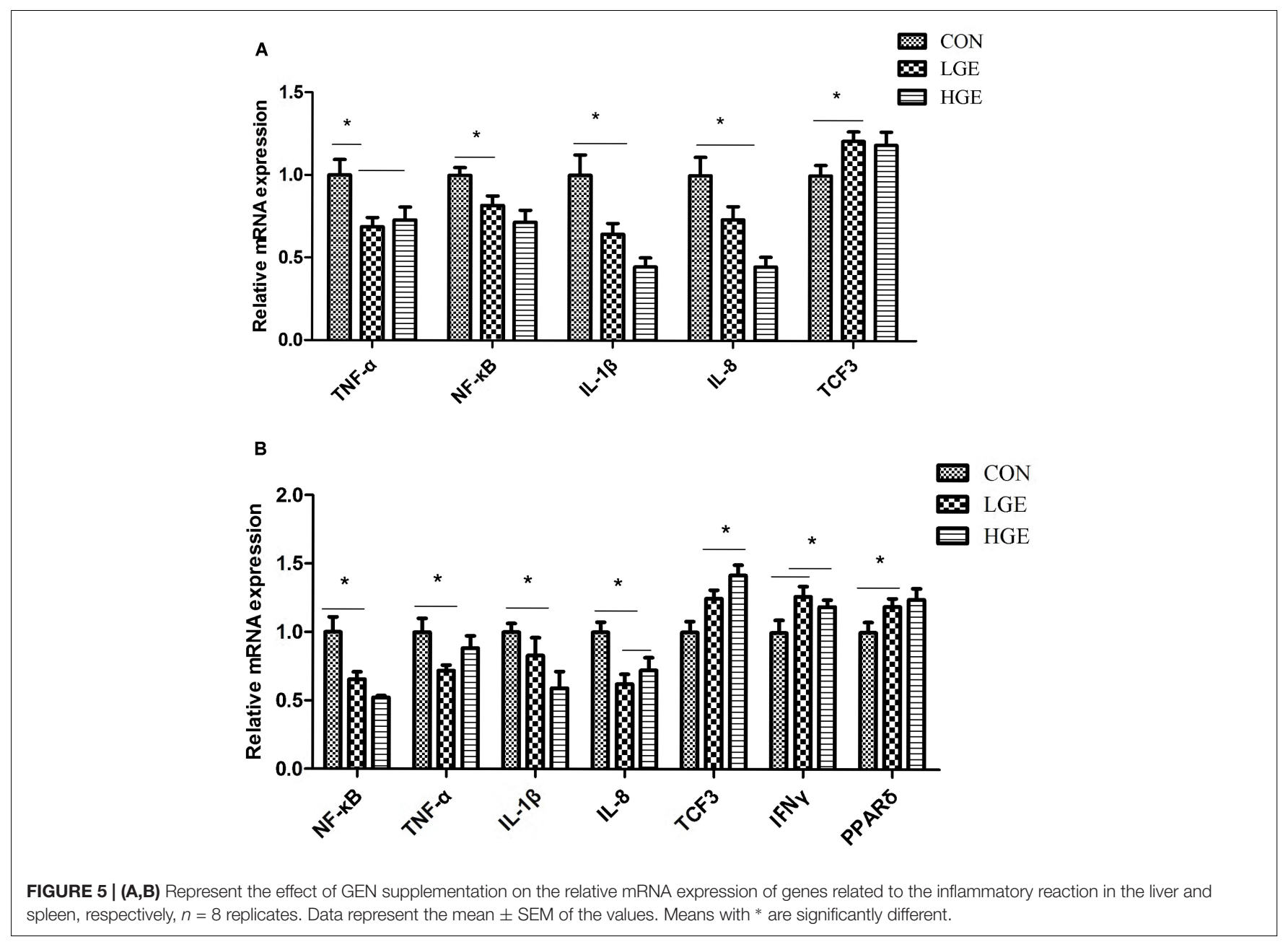

level of PPAR $\gamma$ in the abdominal fat and liver. Therefore, the abdominal fat rate and liver TG content of layers were decreased after GEN treatment. HMGCoAS is the key enzyme that catalyzes the de novo synthesis of cholesterol, which increases the fat content of the liver (Okey, 1933). A prior study showed that PPAR $\alpha$ could inhibit expression of the gene encoding HMGCoAS (Fiorucci et al., 2010), and we found that dietary GEN also downregulated HMGCoAS mRNA expression in the liver. The levels of TC in the serum were significantly decreased after GEN treatment. AFABP, the target gene of $\operatorname{PPAR} \gamma$, promotes lipid deposition in adipocytes. In the present study, dietary supplementation with high and low doses of GEN significantly reduced the mRNA expression of AFABP in the abdominal fat of FLS layers. Thus, the abdominal fat rate was significantly decreased by GEN treatment. In addition, dietary GEN downregulated the expression of Wnt5a in the livers of FLS layers. GEN has been reported to inhibit the Wnt signaling pathway through epigenetic modification (Zhang et al., 2013). Interestingly, activation of the $\mathrm{Wnt} / \beta$-catenin signaling pathway can inhibit $\beta$-oxidation through PPARs (Duval et al., 2004; Essers et al., 2005; Haluzík and Haluzík, 2006). Therefore, GEN might also indirectly activate PPARs through the Wnt signaling pathway, thus alleviating the fat accumulation typical in FLS hens. FFAs and the PPAR signaling pathway regulate each other. Studies have shown that PUFAs can activate PPAR $\alpha$ to upregulate the transcription of genes involved in $\beta$-oxidation and downregulate the expression of genes involved in hepatic fat synthesis (Buang et al., 2004). PUFAs can also promote ApoB-100 secretion and enhance TG transport into the liver (Videla et al., 2004). In particular, n-3 PUFAs can increase insulin sensitivity and improve disordered lipid metabolism. Therefore, GEN treatment might further alleviate FLS through PUFAs.

Fatty acid accumulation is not only a characteristic feature of the FLS but also causes insulin resistance, lipid peroxidation, and an inflammatory response (Randle et al., 1963; Sotovaca et al., 2013). FFAs can stimulate the translocation of Bax into lysosomes, promote the release of cathepsin B into the cytoplasm, and then upregulate the expression of TNF- $\alpha$ through NF- $\kappa$ B. TNF- $\alpha$ can induce the accumulation of TG in the liver, leading to hepatocyte steatosis. TNF- $\alpha$ can also promote lysosomal permeability and activate $\mathrm{NF}-\kappa \mathrm{B}$, thus perpetuating a vicious cycle of liver injury (Feldstein et al., 2004). Pathological analysis revealed inflammatory cell infiltration around the blood vessels in the fatty livers of layers fed with an HELC diet. TNF- $\alpha$ is the first pro-inflammatory factor released in the immune 
response (Zeng et al., 2014) and can also increase ROS in the liver and induce lipid peroxidation (Crews et al., 2006). In the present study, GEN treatment significantly increased SOD activity and the total antioxidant capacity in hens' livers, which was consistent with the report that soybean ISOs could improve SOD activity in RBCs (Chen et al., 2004). MDA can interact with NF- $\kappa \mathrm{B}$ to increase the release of TNF- $\alpha$ (Kishore et al., 2002). Our results showed that dietary GEN supplementation significantly reduced the level of MDA in the livers of FLS layers, reflecting alleviation of lipid peroxidative injury. Additionally, GEN treatment downregulated the expression of TNF- $\alpha$ and $\mathrm{NF}-\kappa \mathrm{B}$ in the livers and spleens of FLS layers. Therefore, the increased antioxidant capacity induced by GEN can relieve the inflammatory response in FLS layers. TNF- $\alpha$ can induce the release of IL- 6 and IL- 8 from Kupffer cells in the liver. It is reported that excessive deposition of palmitic acid in the liver can activate NF- $\kappa \mathrm{B}$ and c-Jun N-terminal kinase-1 (JNK-1) and increase the IL-8 level, leading to an inflammatory reaction (Joshibarve et al., 2007). n-3 PUFAs in the liver have been suggested to alleviate the inflammatory response in obese mice (Hamamoto et al., 1993). In our study, the content of LSFAs (specifically, palmitic acid) in the liver was reduced and the content of n-3 PUFAs was increased by GEN treatment. The mRNA expression of pro-inflammatory factors (IL-8, IL-1 $\beta$ ) in the liver and spleen was also decreased after GEN treatment, as were the organ indices. The deficiency of IL- $1 \beta$ and inflammatory corpuscle components could impede the inflammatory response induced by the fatty liver (Kamari et al., 2011; Vandanmagsar et al., 2011). From routine blood tests and serum biochemical indices, we can see that a high dose of GEN increased the RBC, PLT, PCT, and WBC in the blood of FLS layers. Low-dose GEN treatment increased BASO and reduced LUC compared with the control values. These results further confirmed that the GEN treatment could alleviate the inflammatory response in FLS layers. We further examined the upstream regulatory genes of pro-inflammatory factors. Interesting, the expression levels of PPAR $\delta$ in both liver and spleen tissue were downregulated after GEN treatment, which was consistent with the change in pro-inflammatory factors. It is reported that PPAR $\delta$ can mitigate the inflammatory response by inhibiting $\mathrm{NF}-\kappa \mathrm{B}$ expression (Hoekstra et al., 2009). Similarly, activation of PPAR $\delta$ can delay the production of inflammatory factors, such as TNF- $\alpha$, at injury sites, regulate the adaptation of cells to stress, and prevent the apoptotic signals caused by inflammatory factors (Wahli, 2002). Therefore, dietary GEN can directly inhibit the NF-êB signaling pathway and decrease pro-inflammatory factors by activating PPAR $\delta$. Moreover, high and low doses of GEN significantly increased the transcription levels of IFN $\gamma$ and TCF3 in the liver and spleen. It is well known that IFN- $\gamma$ plays an important role in disease resistance and the immune response in chickens. E proteins, which belong to class I of the basic helix-loop-helix (bHLH) family of transcription factors, are encoded by the TCF3 gene, which is required for lymphocyte proliferation (Henthorn et al., 1990). The TCF3 gene can also inhibit the Wnt signaling pathway (Lluis et al., 2011). Therefore, dietary GEN might regulate inflammatory factors and the Wnt signaling pathway through TCF3, but the interactions between them remain to be studied further. In the present study, dietary GEN supplementation had no significant effects on antibody titers, perhaps because few immunizations were given to the hens during the late laying period. Dietary GEN supplementation indirectly alleviated the FLS in laying hens by improving the antioxidant capacity and regulating the fatty acid profile. In addition, the supplement directly relieved the inflammatory response by regulating the expression of inflammatory factors (IL-8, IL-1 $\beta$, and IFN $\gamma$ ) via PPAR $\delta$ and TCF3.

\section{CONCLUSION}

In conclusion, GEN supplementation in feed inhibited fatty acid synthesis and enhanced $\beta$-oxidation in the livers of layers with FLS through the PPAR-ACAD/ACOT and PPAR-LXR $\alpha$-SREBP1c-ACC/FAS/FAT pathways. Dietary GEN altered the liver fatty acid profile of FLS hens, thereby alleviating fat deposition and lipid metabolism disorder. GEN supplementation improved the antioxidant capacity of layers. We concluded that dietary GEN could indirectly help alleviate the FLS in laying hens by improving the antioxidant capacity and fatty acid profile. Additionally, GEN could directly alleviate the inflammatory response by regulating the expression of inflammatory factors (IL-8, IL- $1 \beta$, and IFN- $\gamma$ ) via PPAR $\delta$ and TCF3. GEN supplementation at $40 \mathrm{mg} / \mathrm{kg}$ of diet can significantly improve the laying rate of hens. This study provides a comprehensive analysis of the effects of dietary GEN on FLS hens from the perspectives of fatty acid metabolism, antioxidation, and the inflammatory response. The optimum dosage range of dietary GEN still needs to be clarified.

\section{ETHICS STATEMENT}

This study was carried out in accordance with the recommendations of Animal Welfare Committee of China Agricultural University (CAU/No. 160515-2). The protocol was approved by the Animal Welfare Committee of China Agricultural University (CAU/No. 160515-2).

\section{AUTHOR CONTRIBUTIONS}

The research was designed and conducted by ZL and YG. The animal experiment was conducted by KX and GL. The detection and analysis works were conducted by ZL and DL. The writing was conducted by ZL independently.

\section{FUNDING}

This research was supported by the China Agricultural Research System Program (CARS-41) and the Chinese Universities Scientific Fund. 


\section{REFERENCES}

Akdemir, F., and Sahin, K. (2009). Genistein supplementation to the quail: effects on egg production and egg yolk genistein, daidzein, and lipid peroxidation levels. Poult. Sci. 88, 2125-2131. doi: 10.3382/ps.200900004

Araya, J., Rodrigo, R., Videla, L. A., Thielemann, L., Orellana, M., Pettinelli, P., et al. (2004). Increase in long-chain polyunsaturated fatty acid $n-6 / n-3$ ratio in relation to hepatic steatosis in patients with non-alcoholic fatty liver disease. Clin. Sci. 106:635.

BerriotVaroqueaux, N., Aggerbeck, L. P., SamsonBouma, M. E., and Wetterau, J. R. (2000). The role of the microsomal triglygeride transfer protein in abetalipoproteinemia. Annu. Rev. Nutr. 20:663.

Bitto, A., Altavilla, D., Bonaiuto, A., Polito, F., Minutoli, L., Di, S. V., et al. (2009). Effects of aglycone genistein in a rat experimental model of postmenopausal metabolic syndrome. J. Endocrinol. 200:367. doi: 10.1677/JOE-080206

Bligh, E. G., and Dyer, W. J. (1959). A rapid method of total lipid extraction and purification. Can. J. Biochem. Physiol. 37:911. doi: 10.1139/y59-099

Bradbury, M. W., and Berk, P. D. (2004). Lipid metabolism in hepatic steatosis. Clin. Liver. Dis. 8, 639-671. doi: 10.1016/j.cld.2004.04.005

Bradford, M. M. (1976). A rapid and sensitive method for the quantification of microgram quantities of protein utilizing principle of proteindye binding. Anal. Biochem. 72, 248-254. doi: 10.1016/0003-2697(76) 90527-3

Buang, Y., Cha, J. Y., Nagao, K., Wang, Y. M., Inoue, N., and Yanagita, T. (2004). Alleviation of fatty liver by alpha-linolenic acid. J. Nutr. Sci. Vitaminol. 50, 272-276. doi: 10.3177/jnsv.50.272

Capanni, M., Calella, F., Biagini, M. R., Genise, S., Raimondi, L., Bedogni, G., et al. (2006). Prolonged npolyunsaturated fatty acid supplementation ameliorates hepatic steatosis in patients with non "lcoholic fatty liver disease: a pilot study. Aliment. Pharmacol. Therapeut. 23, 1143-1151. doi: 10.1111/j.1365-2036.2006. 02885.x

Castellano, J. M., Bentsen, A. H., Sánchezgarrido, M. A., Ruizpino, F., Romero, M., Garciagaliano, D., et al. (2011). Early metabolic programming of puberty onset: impact of changes in postnatal feeding and rearing conditions on the timing of puberty and development of the hypothalamic kisspeptin system. Endocrinology 152, 3396-3408. doi: 10.1210/en.2010-1415

Chapkin, R. S., Davidson, L. A., Ly, L., Weeks, B. R., Lupton, J. R., and Mcmurray, D. N. (2007). Immunomodulatory effects of (n-3) fatty acids: putative link to inflammation and colon cancer. J. Nutr. 137, 200S-204S. doi: 10.1093/jn/137.1. $200 \mathrm{~S}$

Chen, C. Y., Bakhiet, R. M., Hart, V., and Holtzman, G. (2004). Isoflavones restore altered redox homeostasis of antioxidant enzymes in healthy young men undergoing $80 \%$ peak oxygen consumption (VO 2 pk) exercise. Nutr. Res. 24, 347-359. doi: 10.1016/j.nutres.2004.02.001

Chun, O. K., Chung, S. J., Claycombe, K. J., and Song, W. O. (2008). Serum C-reactive protein concentrations are inversely associated with dietary flavonoid intake in U.S. adults. J. Nutr. 138, 753-760. doi: 10.1093/jn/138. 4.753

Crews, F. T., Bechara, R., Brown, L. A., Guidot, D. M., Mandrekar, P., Oak, S., et al. (2006). Cytokines and alcohol. Alcohol. Clin. Exp. Res. 30, 720-730. doi: 10.1111/j.1530-0277.2006.00084.x

Dang, Z., Audinot, V., Papapoulos, S. E., Boutin, J. A., and Löwik, C. W. (2003). Peroxisome proliferator-activated receptor $\gamma(\operatorname{PPAR} \gamma)$ as a molecular target for the soy phytoestrogen genistein. J. Biol. Chem. 278, 962-967. doi: 10.1074/jbc. M209483200

Duval, C., Fruchart, J. C., and Staels, B. (2004). PPAR $\alpha$, fibrates, lipid metabolism and inflammation. Arch. Mal. Coeur. Vaiss. 97, 665-672.

El-Badry, A. M., Graf, R., and Clavien, P. A. (2007). Omega 3 - Omega 6: what is right for the liver? J. Hepatol. 47, 718-725. doi: 10.1016/j.jhep.2007. 08.005

Erickson, S. K. (2009). Nonalcoholic fatty liver disease. J. Lipid Res. 50(Suppl.), S412. doi: 10.1194/jlr.R800089-JLR200

Essers, M. A., de VriesSmits, L. M., Barker, N., Polderman, P. E., Burgering, B. M., and Korswagen, H. C. (2005). Functional interaction between betacatenin and FOXO in oxidative stress signaling. Science 308, 1181-1184. doi: $10.1126 /$ science. 1109083
Fang, Y. C., Chen, B. H., Huang, R. F., and Lu, Y. F. (2004). Effect of genistein supplementation on tissue genistein and lipid peroxidation of serum, liver and low-density lipoprotein in hamsters. J. Nutr. Biochem. 15, 142-148. doi: 10.1016/j.jnutbio.2003.06.001

Feldstein, A. E., Werneburg, N. W., Canbay, A., Guicciardi, M. E., Bronk, S. F., Rydzewski, R., et al. (2004). Free fatty acids promote hepatic lipotoxicity by stimulating TNF-alpha expression via a lysosomal pathway. Hepatology 40, 185-194. doi: 10.1002/hep.20283

Fiorucci, S., Cipriani, S., Baldelli, F., and Mencarelli, A. (2010). Bile acid-activated receptors in the treatment of dyslipidemia and related disorders. Progr. Lipid Res. 49:171. doi: 10.1016/j.plipres.2009.11.001

Giulio, M. M. D., Bugianesi, E., Forlani, G., Cerrelli, F., Lenzi, M., Manini, R., et al. (2003). Nonalcoholic fatty liver, steatohepatitis, and the metabolic syndrome. Hepatology 37, 917-923. doi: 10.1053/jhep.2003.50161

Gudbrandsen, O. A., Wergedahl, H., and Berge, R. K. (2009). A casein diet added isoflavone-enriched soy protein favorably affects biomarkers of steatohepatitis in obese Zucker rats. Nutrition 25, 574-580. doi: 10.1016/j.nut.2008. 10.020

Haluzík, M. M., and Haluzík, M. (2006). PPAR-alpha and insulin sensitivity. Physiol. Res. 55, 115-122.

Hamamoto, I., Nemoto, E. M., Evans, R. W., Mischinger, H. O., Fujita, S., Murase, N., et al. (1993). Rat liver lipids during ex vivo warm and cold ischemia and reperfusion. J. Surg. Res. 55, 382-389. doi: 10.1006/jsre.1993. 1157

Henthorn, P., Mccarrickwalmsley, R., and Kadesch, T. (1990). Sequence of the cDNA encoding ITF-1, a positive-acting transcription factor. Nucleic Acids Res. 18, 678. doi: 10.1093/nar/18.3.678

Hirota, K., Morikawa, K., Hanada, H., Nonaka, M., Nakajima, Y., Kobayashi, M., et al. (2010). Effect of genistein and daidzein on the proliferation and differentiation of human preadipocyte cell line. J. Agric. Food Chem. 58, 5821-5827. doi: 10.1021/jf903911e

Hoekstra, M., Lammers, B., Out, R., Li, Z., Van, E. M., and Van Berkel, T. J. (2009). Activation of the nuclear receptor PXR decreases plasma LDL-cholesterol levels and induces hepatic steatosis in LDL receptor knockout mice. Mol. Pharm. 6, 182-189. doi: $10.1021 / \mathrm{mp} 800131 \mathrm{~d}$

Hunt, M. C., and Alexson, S. E. (2002). The role Acyl-CoA thioesterases play in mediating intracellular lipid metabolism. Progr. Lipid Res. 41, 99-103. doi: 10.1016/S0163-7827(01)00017-0

Hwang, C. S., Loftus, T. M., Mandrup, S., and Lane, M. D. (1997). Adipocyte differentiation and leptin expression. Annu. Rev. Cell Dev. Biol. 13, 231-259. doi: 10.1146/annurev.cellbio.13.1.231

Ichihara, K., and Fukubayashi, Y. (2010). Preparation of fatty acid methyl esters for gas-liquid chromatography. J. Lipid. Res. 51, 635-646. doi: 10.1194/jlr.D00 1065

Jiang, S., Cheng, H. W., Cui, L. Y., Zhou, Z. L., and Hou, J. F. (2013). Changes of blood parameters associated with bone remodeling following experimentally induced fatty liver disorder in laying hens. Poult. Sci. 92, 1443-1453. doi: 10. 3382/ps.2012-02800

Jiang, S., Jiang, Z., Wu, T., Ma, X., Zheng, C., and Zou, S. (2007). Protective effects of a synthetic soybean isoflavone against oxidative damage in chick skeletal muscle cells. Food Chem. 105, 1086-1090. doi: 10.1016/j.foodchem.2007. 05.010

Joshibarve, S., Barve, S. S., Amancherla, K., Gobejishvili, L., Hill, D., Cave, M., et al. (2007). Palmitic acid induces production of proinflammatory cytokine interleukin-8 from hepatocytes. Hepatology 46, 823-830. doi: 10.1002/hep. 21752

Kamari, Y., Shaish, A., Vax, E., Shemesh, S., Kandelkfir, M., Arbel, Y., et al. (2011). Lack of interleukin- $1 \alpha$ or interleukin- $1 \beta$ inhibits transformation of steatosis to steatohepatitis and liver fibrosis in hypercholesterolemic mice. J. Hepatol. 55, 1086-1094. doi: 10.1016/j.jhep.2011.01.048

Khan, S. I., Zhao, J., Khan, I. A., Walker, L. A., and Dasmahapatra, A. K. (2011). Potential utility of natural products as regulators of breast cancer-associated aromatase promoters. Reproduct. Biol. Endocrinol. 9, 1-10. doi: 10.1186/14777827-9-91

Kishore, R., Hill, J. R., McMullen, M. R., Frenkel, J., Nagy, L. E. (2002). ERK1/2 and Egr-1 contribute to increased TNF-alpha production in rat Kupffer cells after chronic ethanol feeding. Am. J. Physiol. Gastrointest Liver Physiol. 282, G6-G15. doi: 10.1152/ajpgi.00328.2001 
Kohjima, M., Enjoji, M., Higuchi, N., Kato, M., Kotoh, K., Yoshimoto, T., et al. (2005). Re-evaluation of fatty acid metabolism-related gene expression in nonalcoholic fatty liver disease. Int. J. Mol. Med. 16, 631-635.

Koteish, A., and Diehl, A. M. (2001). Animal models of steatosis. Semin. Liver Dis. 21, 89-104. doi: 10.1055/s-2001-12932

Kurita, K., Henderson, V. W., Gatz, M., St, J. J., Hodis, H. N., Karim, R., et al. (2016). Association of bilateral oophorectomy with cognitive function in healthy, postmenopausal women. Fertil. Steril. 106, 749.e742-756.e742. doi: 10.1016/j.fertnstert.2016.04.033

Libertini, L. J., and Smith, S. (1978). Purification and properties of a thioesterase from lactating rat mammary gland which modifies the product specificity of fatty acid synthetase. J. Biol. Chem. 253, 1393-1401.

Lluis, F., Ombrato, L., Pedone, E., Pepe, S., Merrill, B. J., and Cosma, M. P. (2011). T-cell factor 3 (Tcf3) deletion increases somatic cell reprogramming by inducing epigenome modifications. Proc. Natl. Acad. Sci. U.S.A. 108, 11912-11917. doi: $10.1073 /$ pnas. 1017402108

Mazur, W. M., Duke, J. A., Wähälä, K., Rasku, S., and Adlercreutz, H. (1998). Isoflavonoids and lignans in legumes: nutritional and health aspects in humans 1. J. Nutr. Biochem. 9, 193-200. doi: 10.1016/S0955-2863(97) 00184-8

Merzdemlow, B. E., Duncan, A. M., Wangen, K. E., Xu, X., Carr, T. P., Phipps, W. R., et al. (2000). Soy isoflavones improve plasma lipids in normocholesterolemic, premenopausal women. Am. J. Clin. Nutr. 71, 1462-1469. doi: 10.1093/ajcn/71.6.1462

Mete, A., Giannitti, F., Barr, B., Woods, L., and Anderson, M. (2013). Causes of mortality in backyard chickens in northern California: 2007-2011. Avian. Dis. 57, 311-315. doi: 10.1637/10382-092312-Case.1

Mezei, O., Banz, W. J., Steger, R. W., Peluso, M. R., Winters, T. A., and Shay, N. (2003). Soy isoflavones exert antidiabetic and hypolipidemic effects through the PPAR pathways in obese Zucker rats and murine RAW 264.7 cells. J. Nutr. 133, 1238-1243. doi: 10.1093/jn/133.5.1238

Miyazawa, S., Furuta, S., Osumi, T., Hashimoto, T., and Nobuo, U. P. (1981). Properties of peroxisomal 3-Ketoacyl-CoA thiolase from rat liver. J. Biochem. 90, 511-519. doi: 10.1093/oxfordjournals.jbchem.a13 3499

Naaz, A., Yellayi, S., Zakroczymski, M. A., Bunick, D., Doerge, D. R., Lubahn, D. B., et al. (2003). The soy isoflavone genistein decreases adipose deposition in mice. Endocrinology 144, 3315-3320. doi: 10.1210/en.20030076

Nakamura, K., Moore, R., Negishi, M., and Sueyoshi, T. (2007). Nuclear pregnane $\mathrm{X}$ receptor cross-talk with FoxA2 to mediate drug-induced regulation of lipid metabolism in fasting mouse liver. J. Biol. Chem. 282, 9768-9776. doi: 10.1074/ jbc.M610072200

Navasa, M., Gordon, D. A., Hariharan, N., Jamil, H., Shigenaga, J. K., Moser, A., et al. (1998). Regulation of microsomal triglyceride transfer protein mRNA expression by endotoxin and cytokines. J. Lipid Res. 39, 1220-1230.

Okey, R. (1933). Effect of cholesterol feeding under varying conditions upon lipids of rat livers. Exp. Biol. Med. 8, 209-215. doi: 10.3181/00379727-30-6770

Øyvind, L. (1991). Studies on Digestion, Deposition and Fatty Acid Composition of Lipids in Cod (Gadus morhua). Bergen: Institute of Nutrition, Directorate of Fisheries, 53.

Park, Y. J., Ko, J. W., Jeon,S., and Hye Kwon,Y. (2013). Genistein alleviates neurodegeneration in ApoE-/- mice fed a high-fat diet. FASEB J. 27(Suppl. 1), 861.22 .

Penza, M., Montani, C., Romani, A., Vignolini, P., Pampaloni, B., Tanini, A., et al. (2006). Genistein affects adipose tissue deposition in a dose-dependent and gender-specific manner. Early. Hum. Dev. 147, 5740-5751.

Pyper, S. R., Viswakarma, N., Yu, S., and Reddy, J. K. (2010). PPAR $\alpha$ : energy combustion, hypolipidemia, inflammation and cancer. Nucl. Recept. Signal. 8:e002. doi: 10.1621/nrs.08002

Randle, P. J., Garland, P. B., Hales, C. N., and Newsholme, E. A. (1963). The glucose fatty-acid cycle. Its role in insulin sensitivity and the metabolic disturbances of diabetes mellitus. Lancet 1:785. doi: 10.1016/S0140-6736(63) 91500-9

Rao, M. S., and Reddy, J. K. (2004). PPAR $\alpha$ in the pathogenesis of fatty liver disease. Hepatology 40, 783-786. doi: 10.1002/hep.20453

Rutkowski, J. M., Davis, K. E., and Scherer, P. E. (2009). Mechanisms of obesity and related pathologies: the macro- and microcirculation of adipose tissue. FEBS J. 276, 5738-5746. doi: 10.1111/j.1742-4658.2009. 07303.x

Sekiya, M., Yahagi, N., Matsuzaka, T., Najima, Y., Nakakuki, M., Nagai, R., et al. (2003). Polyunsaturated fatty acids ameliorate hepatic steatosis in obese mice by SREBP-1 suppression. Hepatology 38, 1529-1539. doi: 10.1053/jhep.2003. 09028

Setchell, K. D., Zimmernechemias, L., Cai, J., and Heubi, J. E. (1998). Isoflavone content of infant formulas and the metabolic fate of these phytoestrogens in early life. Am. J. Clin. Nutr. 68:1453S. doi: 10.1093/ajcn/68.6. $1453 \mathrm{~S}$

Sotovaca, A., Losso, J. N., Mcdonough, K., and Finley, J. W. (2013). Differential effect of 14 free fatty acids in the expression of inflammation markers on human arterial coronary cells. J. Agric. Food Chem. 61, 10074-10079. doi: 10.1021/ jf402966r

Stevenson, L. M., Hess, J. B., Oates, S. S., and Berry, W. D. (2014). A comparison of the effects of estradiol and the soy phytoestrogen genistein on liver lipid content of chickens. Int. J. Poultry Sci. 13, 124-132. doi: 10.3923/ijps.2014.124.132

Stulnig, T. M. (2003). Immunomodulation by polyunsaturated fatty acids: mechanisms and effects. Int. Arch. Aller. Immunol. 132, 310-321. doi: 10.1159/ 000074898

Tang, C., Zhang, K., Zhao, Q., and Zhang, J. (2015). Effects of dietary genistein on plasma and liver lipids, hepatic gene expression, and plasma metabolic profiles of hamsters with diet-induced hyperlipidemia. J. Agric. Food Chem. 63, 7929-7936. doi: 10.1021/acs.jafc.5b01590

Tanoli, T. Y., Pin, Y., Dmitriy, S., and Gustav. (2004). Fatty liver in familial hypobetalipoproteinemia: roles of the APOB defects, intra-abdominal adipose tissue, and insulin sensitivity. J. Lipid Res. 45, 941-947. doi: 10.1194/jlr. M300508-JLR200

Uppenberg, J., Jendeberg, L., and Berkenstam, A. (1999). PPARs: Lipid sensors in metabolic control. Drug News Perspect. 12:389. doi: 10.1358/dnp.1999.12.7. 605743

Vandanmagsar, B., Youm, Y. H., Ravussin, A., Galgani, J. E., Stadler, K., Mynatt, R. L., et al. (2011). The NLRP3 inflammasome instigates obesity-induced inflammation and insulin resistance. Nat. Med. 17, 179-188. doi: 10.1038/nm. 2279

Videla, L. A., Rodrigo, R., Araya, J., and Poniachik, J. (2004). Oxidative stress and depletion of hepatic long-chain polyunsaturated fatty acids may contribute to nonalcoholic fatty liver disease. Free Rad. Biol. Med. 37, 1499-1507. doi: 10.1016/j.freeradbiomed.2004.06.033

Vosper, H., Patel, L., Graham, T. L., Khoudoli, G. A., Hill, A., Macphee, C. H., et al. (2001). The peroxisome proliferator-activated receptor $\delta$ promotes lipid accumulation in human macrophages. J. Biol. Chem. 276, 44258-44265. doi: 10.1074/jbc.M108482200

Wagner, M., Zollner, G., and Trauner, M. T. (2011). Nuclear receptors in liver disease †. Hepatology 53, 1023-1034. doi: 10.1002/hep.24148

Wahli, W. (2002). Peroxisome proliferator-activated receptors (PPARs): from metabolic control to epidermal wound healing. Swiss Med. Weekly 132, 83-91.

Wang, Y. X., Lee, C. H., Tiep, S., Yu, R. T., Ham, J., Kang, H., et al. (2003). Peroxisome-proliferator-activated receptor delta activates fat metabolism to prevent obesity. Cell 113, 159-170. doi: 10.1016/S0092-8674(03)00269-1

Wei, Y., Rector, R. S., Thyfault, J. P., and Ibdah, J. A. (2008). Nonalcoholic fatty liver disease and mitochondrial dysfunction. World J. Gastroenterol. 14, 193-199. doi: $10.3748 /$ wjg.14.193

Willy, P. J., Umesono, K., Ong, E. S., Evans, R. M., Heyman, R. A., and Mangelsdorf, D. J. (1995). LXR, a nuclear receptor that defines a distinct retinoid response pathway. Genes Dev. 9, 1033-1045. doi: 10.1101/gad.9.9.1033

Xu, H. G., Ai, Q. H., Mai, K. S., Wei, X., Wang, J., Ma, H. M., et al. (2010). Effects of dietary arachidonic acid on growth performance, survival, immune response and tissue fatty acid composition of juvenile Japanese seabass, Lateolabrax japonicus. Aquaculture 307, 75-82. doi: 10.1016/j.aquaculture.2010.07.001

Yuan, M. (2001). Reversal of obesity- and diet-induced insulin resistance with salicylates or targeted disruption of Ikk $\beta$. Science 293, 1673-1677. doi: 10.1126/ science. 1061620

Zeng, L., Tang, W. J., Yin, J. J., and Zhou, B. J. (2014). Signal transductions and nonalcoholic fatty liver: a mini-review. Int. J. Clin. Exp. Med. 7, 1624-1631.

Zhang, Y., Li, Q., and Chen, H. (2013). DNA methylation and histone modifications of Wnt genes by genistein during colon cancer development. Carcinogenesis 34, 1756-1763. doi: 10.1093/carcin/bgt129 
Zhang, Y., Liu, Z., Liu, R., Wang, J., Zheng, M., and Li, Q. (2018). Alteration of hepatic gene expression along with the inherited phenotype of acquired fatty liver in chicken. Genes 9:E199. doi: 10.3390/genes9040199

Zhao, X., Shao, T., Wang, Y. Q., Lu, X. L., Luo, J. B., and Zhou, W. D. (2013). The phytoestrogen daidzein may affect reproductive performance of Zhedong White geese by regulating gene mRNA levels in the HPG axis. Br. Poult. Sci. 54, 252-258. doi: 10.1080/00071668.2013.767439

Zhou, J., Febbraio, M., Wada, T., Zhai, Y., Kuruba, R., He, J., et al. (2008). Hepatic fatty acid transporter $\mathrm{Cd} 36$ is a common target of LXR, PXR, and PPARgamma in promoting steatosis. Gastroenterology 134, 556-567. doi: 10.1053/j.gastro. 2007.11.037
Conflict of Interest Statement: The authors declare that the research was conducted in the absence of any commercial or financial relationships that could be construed as a potential conflict of interest.

Copyright (c) $2018 \mathrm{Lv}$, Xing, Li, Liu and Guo. This is an open-access article distributed under the terms of the Creative Commons Attribution License (CC BY). The use, distribution or reproduction in other forums is permitted, provided the original author(s) and the copyright owner(s) are credited and that the original publication in this journal is cited, in accordance with accepted academic practice. No use, distribution or reproduction is permitted which does not comply with these terms. 